\title{
Tourism infrastructure and the environment: how does environmental regulation affect welfare, tourism industry, and domestic wage inequality?
}

\author{
Takanori Shimizu $^{1}$ (D) Hisayuki Okamoto ${ }^{2}$
}

Received: 11 December 2020 / Revised: 27 September 2021 / Accepted: 24 November 2021

(c) Japanese Economic Association 2021

\begin{abstract}
This study presents a general equilibrium model of a small open developing economy with pollution generated by the tourism industry. The national government issues emission permits and constructs tourism infrastructure for the tourism sector. We examine the effects of a stricter environmental regulation on welfare, production, and income distribution. If the elasticity of substitution in the tourism sector is sufficiently low, a stricter environmental regulation paradoxically expands the tourism sector and narrows domestic wage inequality, even under constant tourism terms of trade. In this model, in addition to the two traditional channels, there is a new channel through which a stricter environmental regulation affects the tourism terms of trade and domestic welfare. The new channel, which arises from the difference between the marginal value product of tourism infrastructure and its price, improves the tourism terms of trade and domestic welfare if (1) the marginal value product of tourism infrastructure is greater than its price, (2) the output of tourism infrastructure is increased by a stricter environmental regulation, and (3) the excess supply of a tourism service decreases with a stricter environmental regulation.
\end{abstract}

Keywords Tourism infrastructure $\cdot$ Environmental regulation $\cdot$ Welfare $\cdot$ Wage inequality

JEL Classification D33 · F18 · Q38

Takanori Shimizu

tshimizu@g3s.u-hyogo.ac.jp

Hisayuki Okamoto

hokamoto@sonoda-u.ac.jp

1 Graduate School of Social Sciences, University of Hyogo, 8-2-1 Gakuennishi-machi, Nishi-ku, Kobe, Hyogo 651-2197, Japan

2 Faculty of Business Administration, Sonoda Women's University, 7-29-1

Minamitsukaguchi-cho, Amagasaki, Hyogo 661-8520, Japan 


\section{Introduction}

The tourism industry has become an important sector for both developed and developing countries as it creates employment opportunities and attracts foreign currency. The tourism sector requires a large amount of investment, for example, water supply, sewerage systems, ports, airports, parks, highways, and tourism promotion by authorities (e.g., Visit Japan, Incredible India, and Malaysia Truly Asia), which is rather difficult to be financed only by the private sector. Therefore, a national government needs to construct public infrastructure for the tourism industry, hereafter referred to as tourism infrastructure. At the same time, the tourism sector causes environmental damage. For example, the concentration of people degrades the water quality in the local community, and traffic congestion pollutes the air by the emission of fumes. ${ }^{1,2}$ To mitigate these negative effects, the government introduces an environmental regulation by issuing emission permits to control the amount of pollution. The government can use the revenue from selling pollution permits to construct tourism infrastructure. In general, by reducing the number of emission permits, a stricter environmental regulation tends to discourage the tourism sector, while the formation of tourism infrastructure encourages the sector. A stricter environmental regulation directly improves welfare by reducing the disutility of pollution; at the same time, the price of a tourism service affects consumption patterns and income levels. Thus, it is important to consider the welfare effects of a stricter environmental regulation.

According to ILO (2018, pp. 16-17), the extent of wage inequality-measured by the Gini coefficient-is higher in low- and middle-income countries than in highincome countries. Therefore, rising wage inequality is a serious problem for many developing countries. ${ }^{3}$ This gives rise to the need for developing countries to find a policy that mitigates domestic wage inequality. As pointed out by Aynalem et al. (2016, p. 3), "generally speaking, the tourism and hospitality sector is recognized as having low hourly rates of pay, overtime work without extra money, long working hours of $50 \mathrm{~h}$ per week, little or no adequate breaks during peak season periods." $\mathrm{It}$

\footnotetext{
1 In Japan, especially in Kyoto, an excessive tourism boom has caused over-tourism, bringing serious damages to the local community. However, this congestion phenomenon was suddenly terminated with the outbreak of the COVID-19 pandemic. Since July 2020, the Japanese government started "Go to travel campaign," subsidizing the tourism-related industries. This is expected to increase the number of domestic tourists. In addition, we hope that we will be able to overcome those negative effects of the COVID19 pandemic after a period of time as in the case of the other pandemics in the past such as Spanish flu and Soviet flu. We also believe that there will be rapid growth in inbound tourism as a repercussion of immigration control. Thus, negative aspects of the tourism boom are still worth considering.

${ }^{2}$ For an analysis of the environmental problem in developing countries where international capital flows from developed countries increase domestic pollution, see Beladi et al. (2000).

3 We treat low- and middle-income countries as developing countries.

4 According to Aynalem et al. (2016, p. 3) and UNWTO (2014, p. 28), the tourism employment is characterized by the following factors: (1) seasonality, (2) part-time and/or excessive hours of work, (3) lowpaid (or unpaid) family labor, and (4) informal or sometimes illegal labor where measurement is notably more difficult.
} 
follows that, in addition to the welfare level, the wage gap between the tourism sector and other sectors is one of the most important concerns for policymakers.

In general, an environmental regulation affects the outputs of industries, including the tourism sector, which in turn causes a change in the factor reward employed in each industry and domestic income inequality. However, there are relatively few theoretical analyses of the effect of environmental policy on domestic wage inequality in the presence of tourism. Exceptions include Chao et al. (2012) and Nakai et al. (2018). The present study aims to fill this gap in the literature.

There are many theoretical studies on the analysis of international tourism. In this regard, Copeland (1991) has made a seminal contribution to the literature. Although he analyzed the effect of a tourism boom (an increase in the demand for tourism services by foreign tourists) on the tourism terms of trade (the price of tourism services exported through international tourism) and welfare, the environmental pollution problem was not considered. In recent years, there have been many studies on tourism and the environment, including Beladi et al. (2009), Chao et al. (2008, 2012), Gupta and Dutta (2018), Nakai et al. (2018), Yabuuchi (2013, 2015, 2018), and Yanase (2017). Beladi et al. (2009) constructed a two-good (one traded good and one tourism service) model in which pollution is emitted as a by-product of the tourism service and derived the optimal pollution tax rate that maximizes social welfare. They found that the optimal pollution tax rate does not coincide with the Pigouvian level, that is, the marginal environmental damage to domestic residents. ${ }^{5}$ Chao et al. (2008) considered a three-good (two traded goods and one tourism service) model in which pollution is generated by a manufacturing industry and derived a combination of optimal pollution tax and import tariff. They found that the optimal import tariff rate is positive. By constructing a three-good model in which the tourism sector requires pollution emissions as an input, Yanase (2017) showed that if the excess supply of tourism services rises with a pollution tax, the optimal pollution tax level is lower than the Pigouvian level. By constructing a two-good model where the manufacturing industry is under perfect competition while the tourism sector is under oligopoly, and both tourism and manufacturing industries require pollution permits as an input, Chao et al. (2012) found that if the factor cost share of emission permits in the tourism industry is lower than in the manufacturing sector, a stricter environmental regulation narrows wage inequality. They also showed that if the stricter environmental regulation greatly improves the tourism terms of trade, domestic welfare also improves. In a two-good model where both tourism and manufacturing industries are under perfect competition, Nakai et al. (2018) showed that an improvement in tourism terms of trade narrows domestic wage inequality.

In a three-good Harris-Todaro model where agriculture and tourism industries are located in the rural area and the manufacturing sector is located in the urban area, Yabuuchi (2013) found that a tourism boom (pollution tax) reduces (increases) the urban unemployment rate, which positively (negatively) affects domestic

\footnotetext{
5 Since the pollution tax provides a double dividend in reducing the amount of pollution and improving the tourism terms of trade, the optimal pollution tax rate exceeds the Pigouvian level in the case of exogenous tourism where the spending of foreign tourists is treated as a constant.
} 
welfare. By considering the negative production externality of the tourism industry to agriculture, Yabuuchi (2015) showed that a tourism boom (pollution tax) increases (decreases) the urban unemployment rate. Further, Yabuuchi (2018) introduced a subsidy to agriculture financed by pollution tax, and showed that a tourism boom can reduce the urban unemployment rate if the subsidy rate is sufficiently high relative to the negative externality of the tourism sector.

In a dynamic model of tourism and the environment, Gupta and Dutta (2018) showed that a tourism boom expands the tourism sector in the short run but contracts it in the long run. Meanwhile, Yanase (2015) analyzed the role of infrastructure in the tourism industry in a dynamic setting. He showed that if the economy specializes in the production of tourism services, a tourism boom improves the tourism terms of trade and makes the economy better off. However, he did not consider environmental problems.

The above-mentioned studies on tourism and the environment consider only production-generated pollution. In many studies on trade and the environment, pollution is generated during the production process. For example, Copeland and Taylor (2003) dealt only with production-generated pollution. However, the pollution emitted during consumption should not be neglected. For the analysis of trade and consumption-generated pollution, see Beghin and Roland-Holst (1997) and Copeland (2011, Sect. 6.2). On the one hand, Beghin and Roland-Holst (1997) considered both production-generated and consumption-generated pollution and analyzed the effects of pollution tax (imposed on producers and consumers), trade tax (import tariff), and emission tax on welfare. On the other hand, Copeland (2011, Sect. 6.2) analyzed the welfare effects of emission tax on consumption (differentiated by domestic goods and foreign goods) and trade tax. However, in the above two studies, only traded goods are considered; thus, the good prices are constant under the assumption of a small open economy. In contrast, the price of tourism services (i.e., the tourism terms of trade) is endogenously determined in the domestic market.

In summary, no study has examined the effects of environmental policy on domestic welfare and the wage gap in the presence of tourism infrastructure. The research question in this paper, therefore, is as follows: Does a stricter environmental regulation improve domestic welfare or narrow domestic wage inequality in an economy with tourism infrastructure?

To answer the above question, we present a polluted small open developing economy model with infrastructure in the tourism sector and examine the effects of an environmental regulation on output, income distribution, and welfare. In this study, pollution is an input into tourism service. ${ }^{6}$ The government issues emission permits to the tourism industry and constructs tourism infrastructure. Unskilled labor is a specific input into the tourism service industry. If the elasticity of substitution in the tourism sector is sufficiently low and the tourism terms of trade are constant, a stricter environmental regulation paradoxically expands the tourism industry. In that case, domestic wage inequality narrows as a result of the stricter environmental

\footnotetext{
${ }^{6}$ For an approach treating emission as an input into production, see Beladi et al. (2013), Copeland and Taylor (2003), Ishikawa and Kiyono (2006), and Oladi and Beladi (2015).
} 
regulation. The intuitive reason is as follows. If emission permits are hardly substituted by unskilled labor, a stricter environmental regulation - by decreasing the number of emission permits - greatly raises the price of emission permits, leading to an increase in revenue from selling emission permits. Hence, the government can obtain more resources to construct tourism infrastructure, which increases the output of the tourism service and the wage of unskilled labor.

In this study, we provide a two-final-good model with tourism infrastructure that improves the productivity of the tourism sector. To finance the cost of infrastructure, the Lindahl pricing rule (the price of public intermediate goods is equal to its marginal value product) has been traditionally adopted (Okamoto, 1985). However, this study does not assume the Lindahl pricing rule. Thus, the tangency property with respect to the production possibility curve, the envelope theorem with respect to the revenue function, and the reciprocity relations (the Stolper-Samuelson effect is equal to the Rybczynski effect) do not necessarily hold. ${ }^{7}$ Resultantly, we obtain an interesting result that a stricter environmental regulation may expand the tourism industry. This result does not appear in the existing literature on tourism and the environment.

This study also examines welfare implications. Regarding the tourism terms of trade and the welfare effects of a stricter environmental regulation, two traditional channels have been pointed out by Beladi et al. (2009) and Yanase (2017). Our study includes an additional channel arising from the difference between the marginal value product of tourism infrastructure and its price. It will be shown that the new channel improves the tourism terms of trade and domestic welfare under certain conditions.

The remainder of this paper is organized as follows. In Sect. 2, we describe the setup of the model. Section 3 conducts a comparative statics analysis of the supply side of the economy. In Sect. 4, we examine the effects of a stricter environmental regulation by considering both the supply and demand sides of the economy. Section 5 presents the concluding remarks.

\section{The model}

Consider a small open developing economy that produces a manufacturing good $\mathrm{X}$ and a service $\mathrm{T}$. The manufacturing good is traded while the service is non-traded in the absence of foreign tourists. The service is exported through international tourism, and the manufacturing good is imported. We call service T a tourism service, and its price as the tourism terms of trade. Suppose that the production of the manufacturing good requires capital $\mathrm{K}$ and skilled labor $\mathrm{S}$, while the production of the tourism service requires unskilled labor $\mathrm{L}$ and pollution emission $\mathrm{Z}$. In other words, skilled labor (unskilled labor) is a specific input into the traded good (tourism service) industry. This specification, which is also adopted in Chao et al. $(2010,2012)$,

\footnotetext{
${ }^{7}$ Okamoto (1985) assumed the Lindahl pricing in a general equilibrium model with public intermediate good. In his model, the tangency property holds.
} 
is consistent with the observations of Marjit and Acharyya (2003) and Chao et al. (2010). Marjit and Acharyya (2003, p. 117) pointed out that "most of the non-traded production in the LDCs uses unskilled labour intensively", while Chao et al. (2010, p. 455) stated that "for developing economies, the exportable sector tends to be relatively intensive in unskilled labor". The domestic government collects revenue from selling emission permits and uses this revenue to construct tourism infrastructure. For simplicity, suppose that the tourism infrastructure requires only capital input, ${ }^{8}$ and further assume that the formation of tourism infrastructure only enhances the productivity of the tourism industry. ${ }^{9}$ Therefore, the cost of tourism infrastructure is financed by the user pay principle. In other words, firms in the tourism sector-the beneficiaries of tourism infrastructure- bear the cost through the payment for pollution permits.

The production function of manufacturing good (or traded good) $\mathrm{X}$ is given by

$$
X=X\left(K_{X}, S\right) \text {, }
$$

where $K_{j}$ denotes the capital input into good $j$ and $S$ is the endowment of skilled labor. Function $X$ is assumed to be the neoclassical type of production function that exhibits homogeneity of degree one, and to be strictly quasi-concave.

The production function of the tourism service is given by

$$
T=g(M) N(L, Z) .
$$

Function $N$ has the same properties as function $X$, that is, the neoclassical properties. Moreover, function $g$ represents the positive externality of the infrastructure, $M$ is the amount of tourism infrastructure devoted only to the tourism industry, $L$ is the endowment of unskilled labor, and $Z$ is the amount of pollution. Keeping $M$ unchanged and doubling $L$ and $Z$, the output of tourism service $T$ doubles. This implies that the tourism infrastructure has no congestion effect. This means that the tourism infrastructure in this study is the creation of the atmosphere type in Meade's (1952) terminology. For example, $M$ is considered a tourism promotion campaign by tourism authorities, which reduces advertisement costs. Given the amount of production input, an increase in $M$ results in an increase in the output of the tourism service. Therefore, $g$ is an increasing function of $M$. For the positive externality of intermediate goods or infrastructure, see Okamoto (1985) and Yanase (2015).

We assume $g$ is twice continuously differentiable and has the following properties:

$$
g(0)=1, g^{\prime}>0, g^{\prime \prime}<0, \lim _{M \rightarrow 0} g^{\prime}(M)=\infty, \lim _{M \rightarrow \infty} g^{\prime}(M)=0 .
$$

The first condition implies that if there is no tourism infrastructure, the productivity of the tourism sector does not change. The second and third conditions mean that tourism infrastructure has a positive and diminishing effect on the productivity

\footnotetext{
${ }^{8}$ Even if the tourism sector industry requires both capital and skilled labor, the main results do not change as long as the manufacturing sector is skilled labor intensive relative to the tourism infrastructure sector.

9 Yanase (2015) made the same assumption.
} 
of the tourism sector. Finally, the last two conditions are known as the Inada conditions. Yanase (2015) made a similar assumption.

The production function of tourism infrastructure is

$$
M=K_{M} / a_{K M},
$$

where $a_{i j}$ is the amount of factor $i(=L, S, K, Z)$ to produce one unit of good $j(=X, T, M)$. We assume a linear production function for tourism infrastructure and, thus, $a_{K M}$ is constant.

We now examine the equilibrium conditions for the supply side of the economy. We assume that perfect competition prevails in the manufacturing and tourism industries. The zero-profit condition (the price of the good is equal to its unit cost) for the traded good industry is

$$
a_{S X} w_{S}+a_{K X} q=p_{X}
$$

where $p_{X}$ is the price of traded goods, $w_{S}$ is the wage of skilled labor, and $q$ is the rental rate of capital. Note that $p_{X}$ is constant under the assumption of a small open economy. Applying Shephard's lemma, we obtain the unit requirement of factor $i$ in the production of good $j\left(a_{i j}\right)$ by differentiating the unit cost function with respect to the associated factor price.

The zero-profit condition for the tourism service industry is

$$
a_{L T} w_{L}+a_{Z T} r=p_{T},
$$

where $p_{T}$ is the price of the tourism service, $w_{L}$ the wage of unskilled labor, and $r$ the price of emission permits.

The zero-profit condition for tourism infrastructure sector is ${ }^{10}$

$$
a_{K M} q=p_{M},
$$

where $p_{M}$ is the shadow price of tourism infrastructure.

Next, we consider the factor market equilibrium conditions. Factor endowments are provided exogenously. The full employment condition of capital is

$$
a_{K X} X+a_{K M} M=K .
$$

The demand-supply equality of skilled labor requires

$$
a_{S X} X=S .
$$

The market equilibrium condition of unskilled labor requires

$$
a_{L T} T=L .
$$

The amount of pollution is given by

$$
a_{Z T} T=Z \text {. }
$$

\footnotetext{
${ }^{10}$ Since cost minimization is required in tourism infrastructure sector, cost equals revenue.
} 
Finally, the budget constraint of the government is

$$
r Z=p_{M} M
$$

where the left-hand side (LHS) denotes the revenue from selling emission permits, and the right-hand side (RHS) denotes the cost of constructing tourism infrastructure. Equations (1)-(8) include eight unknowns: $X, T, w_{L}, w_{S}, q, r, p_{M}$, and $M$. Given $p_{T}$, the above eight equations determine eight unknowns. ${ }^{11}$ Note that the price of tourism infrastructure $p_{M}$ is determined to satisfy the government's budget constraint (8). It follows that the traditional Lindahl pricing rule does not necessarily hold; thus, we obtain different properties from the standard trade theory.

To facilitate the following analysis, we introduce the elasticity of factor substitution. The elasticity of substitution in each sector $\sigma_{j}$ is defined as

$$
\begin{gathered}
\sigma_{X}=\frac{\widehat{a}_{K X}-\widehat{a}_{S X}}{\widehat{w}_{S}-\hat{q}}, \\
\sigma_{T}=\frac{\widehat{a}_{Z T}-\widehat{a}_{L T}}{\widehat{w}_{L}-\hat{r}} .
\end{gathered}
$$

A hat over a variable implies the rate of change: for example, $\widehat{w}_{S} \equiv d w_{S} / w_{S}$.

The cost minimization in each sector requires ${ }^{12}$

$$
\begin{gathered}
\theta_{S X} \widehat{a}_{S X}+\theta_{K X} \widehat{a}_{K X}=0, \\
\theta_{L T} \widehat{a}_{L T}+\theta_{Z T} \widehat{a}_{Z T}=-\widehat{g},
\end{gathered}
$$

where $\theta_{i j}$ represents the cost share of factor $i$ in sector $j$.

Solving Eqs. (9) and (11), we obtain

$$
\begin{gathered}
\widehat{a}_{S X}=-\theta_{K X} \sigma_{X}\left(\widehat{w}_{S}-\hat{q}\right), \\
\widehat{a}_{K X}=\theta_{S X} \sigma_{X}\left(\widehat{w}_{S}-\hat{q}\right) .
\end{gathered}
$$

Similarly, solving Eqs. (10) and (12), we have

$$
\begin{gathered}
\widehat{a}_{L T}=-\theta_{Z T} \sigma_{T}\left(\widehat{w}_{L}-\widehat{r}\right)-\widehat{g}, \\
\hat{a}_{Z T}=\theta_{L T} \sigma_{T}\left(\widehat{w}_{L}-\widehat{r}\right)-\widehat{g} .
\end{gathered}
$$

\footnotetext{
11 The price of tourism service $p_{T}$ is to be determined by the demand and supply of domestic tourism service in Sect. 4. This approach is adopted by Chao et al. (2010).

12 Note that $w_{L} d a_{L N}+r d a_{Z N}=0$ holds by the cost minimization in the tourism sector since each firm in that sector does not take into account the positive externality of tourism infrastructure, where $a_{L N} \equiv g \cdot a_{L T}$ and $a_{Z N} \equiv g \cdot a_{Z T}$ are input coefficients of the tourism industry in the absence of tourism infrastructure.
} 
Differentiating Eq. (1) totally and taking into account Eq. (11), we obtain

$$
\theta_{S X} \widehat{w}_{S}+\theta_{K X} \widehat{q}=\widehat{p}_{X}
$$

Differentiating Eq. (2) totally and considering Eq. (12), we obtain

$$
\theta_{L T} \widehat{w}_{L}+\theta_{Z T} \widehat{r}-\xi \widehat{M}=\widehat{p}_{T},
$$

where $\xi \equiv \frac{g^{\prime} M}{g}>0$ denotes the elasticity of $g$ with respect to $M$, or the productivity improvement rate of the tourism industry by additional tourism infrastructure. By definition, $\widehat{g}=\xi \widehat{M}$ holds.

Since $a_{K M}$ is constant, Eq. (3) implies

$$
\hat{p}_{M}=\widehat{q}
$$

Differentiating Eq. (4) and substituting Eq. (14), we obtain

$$
\lambda_{K X} \widehat{X}+\lambda_{K X} \theta_{S X} \sigma_{X}\left(\widehat{w}_{S}-\widehat{q}\right)+\lambda_{K M} \widehat{M}=\widehat{K},
$$

where $\lambda_{i j}$ is the share of factor $i$ in the production of good $j$.

Differentiating Eq. (5) and substituting Eq. (13), we obtain

$$
-\theta_{K X} \sigma_{X}\left(\widehat{w}_{S}-\widehat{q}\right)+\widehat{X}=\widehat{S} .
$$

Differentiating Eq. (6) and using Eq. (15), we have

$$
-\theta_{Z T} \sigma_{T}\left(\widehat{w}_{L}-\widehat{r}\right)-\xi \widehat{M}+\widehat{T}=\widehat{L}
$$

Differentiating Eq. (7) and substituting Eq. (16), we obtain

$$
\theta_{L T} \sigma_{T}\left(\widehat{w}_{L}-\widehat{r}\right)-\xi \hat{M}+\widehat{T}=\widehat{Z}
$$

Differentiating Eq. (8) and considering Eq. (19), we obtain

$$
\widehat{q}+\widehat{M}-\widehat{r}=\widehat{Z} \text {. }
$$

Equations (17), (18), and (20)-(24) are expressed in matrix form as follows:

$$
\left(\begin{array}{ccccccc}
0 & 0 & 0 & \theta_{S X} & 0 & \theta_{K X} & 0 \\
0 & 0 & -\xi & 0 & \theta_{L T} & 0 & \theta_{Z T} \\
\lambda_{K X} & 0 & \lambda_{K M} & \lambda_{K X} \theta_{S X} \sigma_{X} & 0 & -\lambda_{K X} \theta_{S X} \sigma_{X} & 0 \\
1 & 0 & 0 & -\theta_{K X} \sigma_{X} & 0 & \theta_{K X} \sigma_{X} & 0 \\
0 & 1 & -\xi & 0 & -\theta_{Z T} \sigma_{T} & 0 & \theta_{Z T} \sigma_{T} \\
0 & 1 & -\xi & 0 & \theta_{L T} \sigma_{T} & 0 & -\theta_{L T} \sigma_{T} \\
0 & 0 & 1 & 0 & 0 & 1 & -1
\end{array}\right)\left(\begin{array}{c}
\widehat{X} \\
\widehat{T} \\
\widehat{M} \\
\widehat{w}_{S} \\
\widehat{w}_{L} \\
\widehat{q} \\
\widehat{r}
\end{array}\right)=\left(\begin{array}{c}
\hat{p}_{X} \\
\hat{p}_{T} \\
\widehat{K} \\
\widehat{S} \\
\widehat{L} \\
\widehat{Z} \\
\widehat{Z}
\end{array}\right)
$$

This is the system of the equations describing the supply side of the economy. 


\section{Comparative statics: supply side analysis}

The supply side of the economy (Eqs. (1)-(8)) determines the outputs and factor prices (and, therefore, factor demands). In this section, utilizing Eq. (25), we examine the effects of a stricter environmental regulation and an improvement in the tourism terms of trade on outputs and factor prices.

\subsection{Environmental regulation}

In this subsection, we consider the effects of a stricter environmental regulation. A stricter environmental regulation means a reduction in emission permits in this regard $(d Z<0)$.

From Eq. (17), we have

$$
\widehat{q}=-\frac{\theta_{S X}}{\theta_{K X}} \widehat{w}_{S}
$$

Since $p_{X}$ is unchanged, an increase in the skilled wage is balanced by a decrease in the rental rate of capital. Equation (26) implies $\widehat{w}_{S}-\widehat{q}=\widehat{w}_{S} / \theta_{K X}$. From Eq. (21), we have

$$
\widehat{X}=\theta_{K X} \sigma_{X}\left(\widehat{w}_{S}-\widehat{q}\right)=\sigma_{X} \widehat{w}_{S}
$$

This means that an increase in the output of traded good $X$ raises the wage of skilled labor, which is a specific input to that sector.

Substituting Eqs. (26) and (27) into Eq. (20), we obtain

$$
\widehat{M}=-\frac{\lambda_{K X} \sigma_{X}}{\lambda_{K M} \theta_{K X}} \widehat{w}_{S}=-\frac{\lambda_{K X}}{\lambda_{K M} \theta_{K X}} \widehat{X},
$$

which states that an increase in the output of traded good reduces the output of tourism infrastructure by extracting capital input from that industry. Equations (26)-(28) show that $\widehat{q}, \widehat{X}$, and $\widehat{M}$ are proportional to $\widehat{w}_{S}$.

From Eqs. (22) and (23), we have

$$
\widehat{w}_{L}-\widehat{r}=\frac{\widehat{Z}}{\sigma_{T}},
$$

which implies that if the number of pollution permits is unchanged, $\widehat{w}_{L}=\widehat{r}$ holds.

Solving Eq. (25), we obtain (see Appendix A)

$$
\begin{gathered}
\frac{\widehat{T}}{\widehat{Z}}=\frac{\sigma_{T}\left[\left(\theta_{Z T}+\xi \theta_{L T}\right) \lambda_{K X} \sigma_{X}+\theta_{S X} \theta_{Z T} \lambda_{K M}\right]-\xi \theta_{L T} \lambda_{K X} \sigma_{X}}{\Delta}, \\
\frac{\widehat{w}_{S}}{\widehat{Z}}=\frac{\theta_{K X} \lambda_{K M}\left(\theta_{L T}-\sigma_{T}\right)}{\Delta},
\end{gathered}
$$




$$
\begin{gathered}
\frac{\widehat{w}_{L}}{\widehat{Z}}=\frac{\lambda_{K X} \sigma_{X}\left[\theta_{Z T}+\xi\left(\sigma_{T}-1\right)\right]+\lambda_{K M} \theta_{S X} \theta_{Z T}}{\Delta} \\
\frac{\widehat{r}}{\widehat{Z}}=\frac{\xi \sigma_{T} \lambda_{K X} \sigma_{X}-\theta_{L T} \lambda_{K M} \theta_{S X}-\lambda_{K X} \sigma_{X} \theta_{L T}}{\Delta}=\frac{\lambda_{K X} \sigma_{X}\left(\xi \sigma_{T}-\theta_{L T}\right)-\theta_{L T} \lambda_{K M} \theta_{S X}}{\Delta}
\end{gathered}
$$

where $\Delta \equiv \sigma_{T}\left[\lambda_{K X} \sigma_{X}(1-\xi)+\lambda_{K M} \theta_{S X}\right]>0 .{ }^{13}$

The qualitative effects of a reduction in emissions are ambiguous and depend on the elasticity of substitution in the tourism sector $\sigma_{T}$. From Eq. (30), a reduction in emissions decreases the production of the tourism service if and only if

$$
\sigma_{T}>\frac{\xi \lambda_{K X} \sigma_{X} \theta_{L T}}{\lambda_{K X} \sigma_{X} \theta_{Z T}+\xi \lambda_{K X} \sigma_{X} \theta_{L T}+\lambda_{K M} \theta_{S X} \theta_{Z T}} \equiv A .
$$

We can immediately show that $A<\theta_{L T}$.

From Eq. (32), the necessary and sufficient condition for a reduction in emissions to decrease the wage of unskilled labor is

$$
\sigma_{T}>1-\frac{\theta_{Z T}}{\xi}-\frac{\lambda_{K M} \theta_{S X} \theta_{Z T}}{\lambda_{K X} \sigma_{X} \xi} \equiv B
$$

Using Eq. (33), a reduction in emission decreases the price of emission permits if and only if

$$
\sigma_{T}>\frac{\theta_{L T}}{\xi}+\frac{\lambda_{K M} \theta_{S X} \theta_{L T}}{\lambda_{K X} \sigma_{X} \xi} \equiv C
$$

Since $\xi<1, C>\theta_{L T}$ holds.

It is straightforward to show that $A>B$ since

$$
A-B=\frac{\xi \theta_{L T}}{\theta_{Z T}+\xi \theta_{L T}+m}-1+\frac{\theta_{Z T}}{\xi}+\frac{m}{\xi}=\frac{\left(\theta_{Z T}+m\right)\left[(1-\xi) \theta_{Z T}+m\right]}{\xi\left(\theta_{Z T}+\xi \theta_{L T}+m\right)}>0,
$$

where $m \equiv \frac{\lambda_{K M} \theta_{S X} \theta_{Z T}}{\lambda_{K X} \sigma_{X}}>0$.

Therefore, we have the following relationships in magnitude:

$$
B<A<\theta_{L T}<C .
$$

The above results are summarized in Table 1, which shows how the comparative static results with respect to $Z$ depend on $\sigma_{T}$, with threshold values such as $B, A, \theta_{L T}$, and $C$.

The intuition for the above results is as follows. When the elasticity of substitution in the tourism sector $\sigma_{T}$ is sufficiently low, a decrease in emission permits $Z$ raises its price $r$ significantly since pollution is hardly substituted by unskilled

$\overline{13}$ From the assumptions $g^{\prime \prime}<0$ and $g(0)=1$, we have $\xi<1$. 
labor. Therefore, the revenue from selling emission permits $r Z$ and the output of tourism infrastructure $M$ increases (see Eq. (8)). ${ }^{14}$ If an increase in $M$ is significant, the output of tourism industry $T$ rises despite the reduction in emission permits $Z$. Consequently, the wage of unskilled labor, which is a specific factor into the tourism sector, increases. At the same time, capital flows from the manufacturing sector, leading to a decrease in the output of manufacturing good $X$. The decrease in the output of the manufacturing good reduces the wage of skilled labor, which is a specific factor into that industry. Since the price of the manufacturing good is constant, the decrease in the wage of skilled labor is balanced by the increase in the rental rate of capital (see Eq. (17)).

When $\sigma_{T}$ is sufficiently high, the stricter environmental regulation decreases permit price $r$ since the demand for emission permits is largely substituted by unskilled labor. Thus, the revenue from emission permits and the output of tourism infrastructure decrease. It follows that the output of the tourism service falls due to a decrease in both emission permits and positive externality of tourism infrastructure. Additionally, the wage of unskilled labor decreases despite the initial increase in demand. Meanwhile, capital flows from the tourism infrastructure sector to the manufacturing sector, leading to an increase in the output of the manufacturing sector. The increased output of the manufacturing good raises the wage of skilled labor due to an increase in demand.

Thus, we have the following proposition.

Proposition 1 Suppose that the tourism terms of trade $p_{T}$ are constant. When the elasticity of substitution in the tourism sector is sufficiently low, a stricter environmental regulation expands the tourism and tourism infrastructure sectors and contracts the manufacturing sector. This narrows the wage inequality between skilled and unskilled labor. The rental rate of capital and the price of emission permits rise. As the elasticity of substitution in the tourism sector increases, all the above results are reversed.

The effects on the output of the tourism service and the unskilled wage rate also depend on the positive externality of tourism infrastructure $\xi$. When $\sigma_{T}<\theta_{L T}$, a stricter environmental regulation raises the output of tourism infrastructure $M$. If $\xi$ is sufficiently high, the output of the tourism service significantly increases, and the wage of unskilled labor rises. In other words, the higher $\xi$ is, the higher the possibility of an increase in the output of the tourism service and the unskilled wage rate. When $\sigma_{T}>\theta_{L T}$, both the output of the tourism service and the unskilled wage rate unambiguously decrease since $B<A<\theta_{L T}<\sigma_{T}$. In this case, the output of the tourism service falls due to a decrease in both pollution permits and positive externality of tourism infrastructure.

Similarly, the effect on the price of emission permits depends on $\xi$. When $\sigma_{T}>\theta_{L T}$, the output of tourism infrastructure is decreased by the stricter environmental regulation. If $\xi$ is sufficiently high, the drop in the output of the tourism service increases. Subsequently, the price of emission permits decreases since

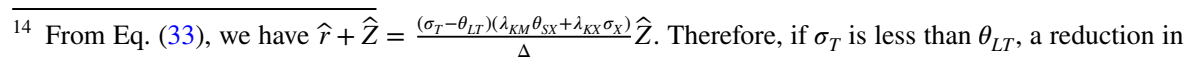
emission raises the revenue from selling emission permits $r Z$.
} 
Table 1 The effects of a reduction in $Z$

\begin{tabular}{llllllllll}
\hline$\sigma_{T}$ & - & $B$ & - & $A$ & - & $\theta_{L T}$ & - & $C$ & - \\
\hline$\widehat{X}$ & - & - & - & - & - & 0 & + & + & + \\
$\widehat{T}$ & + & + & + & 0 & - & - & - & - & - \\
$\widehat{M}$ & + & + & + & + & + & 0 & - & - & - \\
$\widehat{w}_{S}$ & - & - & - & - & - & 0 & + & + & + \\
$\widehat{w}_{L}$ & + & 0 & - & - & - & - & - & - & - \\
$\widehat{q}$ & + & + & + & + & + & 0 & - & - & - \\
$\widehat{r}$ & + & + & + & + & + & + & + & 0 & - \\
\hline
\end{tabular}

a decline in demand for emission permits outweighs the decrease in supply. When $\sigma_{T}<\theta_{L T}$, the output of tourism infrastructure increases and the price of emission permits unambiguously rises because $\sigma_{T}<\theta_{L T}<C$. This means that the decrease in the supply of emission permits increases the price of emission permits even when the output of the tourism service falls.

In particular, the case of $\widehat{T} / \widehat{Z}<0$ (the stricter environmental regulation increases the output of the tourism service) is paradoxical in the usual sense because pollution emission is a specific input into the tourism industry, and we try to explain this result graphically. For this purpose, we introduce the production possibility curve or the transformation curve. The properties of the production possibility curve in our model are proved in Appendix B and summarized in the following proposition.

Proposition 2 The production possibility curve in our model is flatter (steeper) than the price line if and only if the marginal value product of tourism infrastructure is greater (lesser) than its price. The curve is strictly concave to the origin.

In the absence of the Lindahl pricing rule, the tangency property with respect to the production possibility curve does not necessarily hold. From Eq. (8), we obtain $p_{T} \frac{\partial T}{\partial M}-p_{M}=p_{M}\left(\frac{\xi}{\theta_{Z T}}-1\right)$. It follows that the Lindahl pricing requires $\xi=\theta_{Z T}$; otherwise, the marginal value product of tourism infrastructure is greater (lesser) than its price if and only if $\xi>(<) \theta_{Z T}$. In what follows, we focus on the case of $\xi>\theta_{Z T}$ since the national government otherwise has no incentive to construct tourism infrastructure. The initial production possibility curve is depicted by curve ABC. See Figs. 1 and 2. When $Z$ is decreased, the curve shifts inward to AB'C'. At the same time, the price line shifts upward if the elasticity of substitution in the tourism sector is sufficiently low; otherwise, it shifts downward. ${ }^{15}$ Accordingly, the production

\footnotetext{
15 The total revenue $R$ is given by $R=p_{X} X+p_{T} T$, which is depicted by the price line in the $(T, X)$ plane. The slope of the price line is equal to $-p_{T} / p_{X}$. An increase (A decrease) in $R$ shifts upward (downward) the price line. See Figs. 1 and 2 . The change in total revenue due to the stricter environmental regulation is $\frac{\partial R}{\partial Z} \equiv R_{Z}=r+p_{M}\left(\frac{\xi}{\theta_{Z T}}-1\right) \frac{\partial M}{\partial Z}$ (See Eq. (C.3) of Appendix C). The first term is positive while the second is negative (recall that $p_{M}\left(\frac{\xi}{\theta_{Z T}}-1\right)>0$ and $\frac{\partial M}{\partial Z}<0$ ). Note that the lesser the elasticity of substitution in the tourism sector $\sigma_{T}$, the greater the absolute value of $\frac{\partial M}{\partial Z}$.
} 
point moves from point B to B', leading to a decrease in $X$ and an increase in $T$. Figure 1 (Fig. 2) corresponds to the case where the stricter environmental regulation decreases (increases) total revenue.

\subsection{Improvement in the tourism terms of trade}

In this subsection, we investigate the effects of an improvement in the tourism terms of trade $p_{T}$. Note that Eqs. (26), (27), and (28) still hold. Substituting Eqs. (26) and (28) into Eq. (24), we obtain

$$
\frac{\widehat{r}}{\hat{p}_{T}}=\frac{\widehat{q}}{\hat{p}_{T}}+\frac{\widehat{M}}{\hat{p}_{T}}=-\frac{\lambda_{K M} \theta_{S X}+\lambda_{K X} \sigma_{X}}{\lambda_{K M} \theta_{K X}} \frac{\widehat{w}_{S}}{\hat{p}_{T}} .
$$

Equation (29) implies $\widehat{w}_{L} / \widehat{p}_{T}=\widehat{r} / \widehat{p}_{T}$.

Substituting Eq. (28) into Eq. (22) and considering $\widehat{w}_{L} / \widehat{p}_{T}-\widehat{r} / \widehat{p}_{T}=0$ from Eq. (29), we have

$$
\frac{\widehat{T}}{\hat{p}_{T}}=\xi \frac{\widehat{M}}{\hat{p}_{T}}=-\xi \frac{\lambda_{K X} \sigma_{X}}{\lambda_{K M} \theta_{K X}} \frac{\widehat{w}_{S}}{\hat{p}_{T}} .
$$

Solving Eq. (25), we obtain (see Appendix A)

$$
\frac{\widehat{w}_{S}}{\widehat{p}_{T}}=-\frac{\theta_{K X} \lambda_{K M} \sigma_{T}}{\Delta}<0 .
$$

The effects of improvement in the tourism terms of trade on the price of emission permits and the wage of unskilled labor have magnification effects $\left(\hat{r} / \hat{p}_{T}=\widehat{w}_{L} / \hat{p}_{T}>1\right)$. This result is different from that of Nakai et al. (2018), where pollution is a general input to both manufacturing and tourism industries, while unskilled labor is a specific input into the tourism sector. In Nakai et al. (2018), the effects of improvement in the tourism terms of trade have a magnification effect on the wages of unskilled labor $\left(\widehat{w}_{L} / \widehat{p}_{T}>1\right)$, and not on the price of emission permits $\left(\hat{r} / \widehat{p}_{T}<1\right)$.

Since we do not assume the Lindahl pricing rule, the traditional reciprocity relationship (i.e., $\partial T / \partial Z=\partial r / \partial p_{T}$ ) does not necessarily hold. ${ }^{16}$ Therefore, we have obtained an interesting result that the stricter environmental regulation may expand the tourism sector.

The effects of an increase in $p_{T}$ are summarized in Table 2 and proposition 3.

\footnotetext{
${ }^{16}$ In the presence of the Lindahl pricing rule $\left(p_{T} \frac{\partial T}{\partial M}=p_{M}\right)$, the usual tangency property $\left(\frac{\partial R}{\partial p_{T}}=T\right.$ and $\frac{\partial R}{\partial Z}=r$ ) always holds (see Appendix C), where $R$ - the total revenue-is also the revenue function (to be defined in Sect. 4.1). By applying the Young's theorem to the revenue function, we obtain the reciprocity relationship: $\frac{\partial T}{\partial Z}=\frac{\partial^{2} R}{\partial Z \partial p_{T}}=\frac{\partial^{2} R}{\partial p_{T} \partial Z}=\frac{\partial r}{\partial p_{T}}$. However, if $p_{T} \frac{\partial T}{\partial M} \neq p_{M}$, the reciprocity relationship does not hold except in the special case of $\sigma_{T}=1$ (see Appendix E).
} 


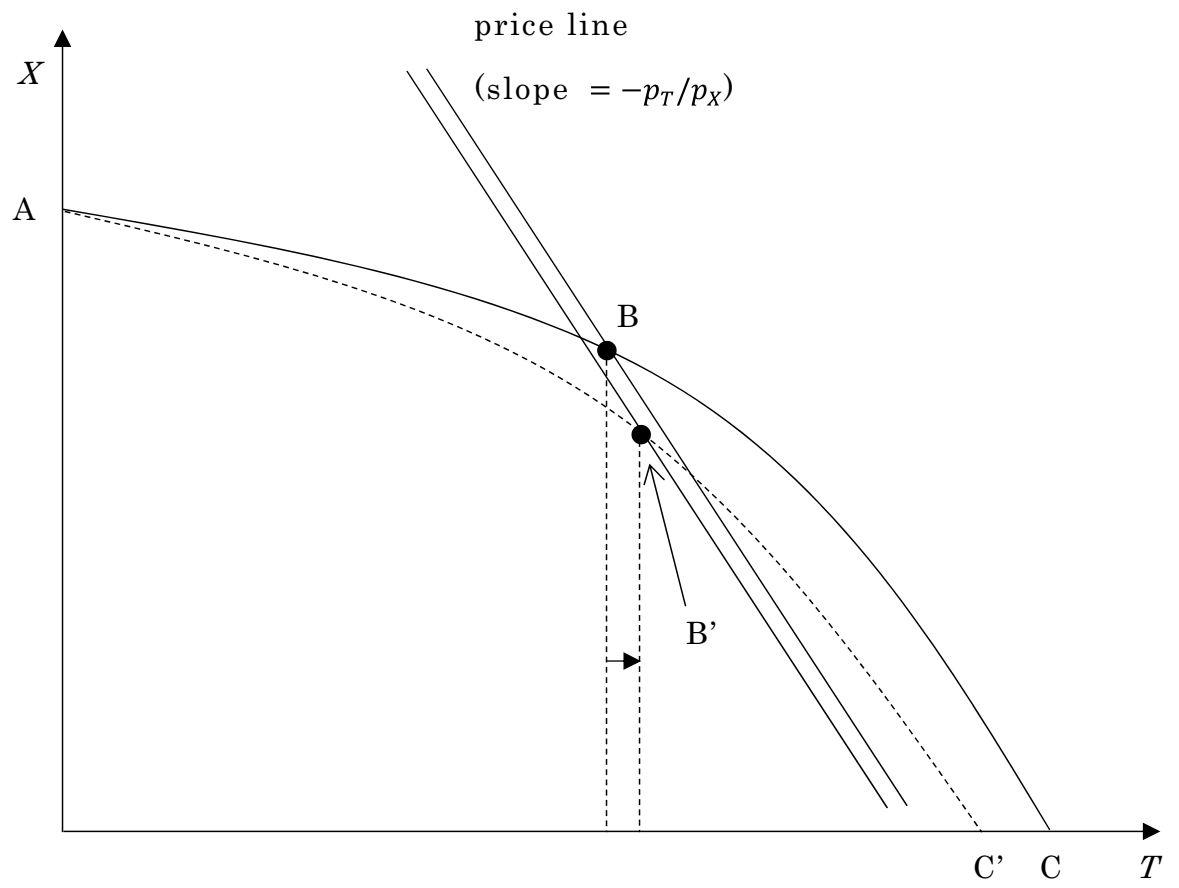

Fig. 1 The case of a stricter environmental regulation decreasing the total revenue

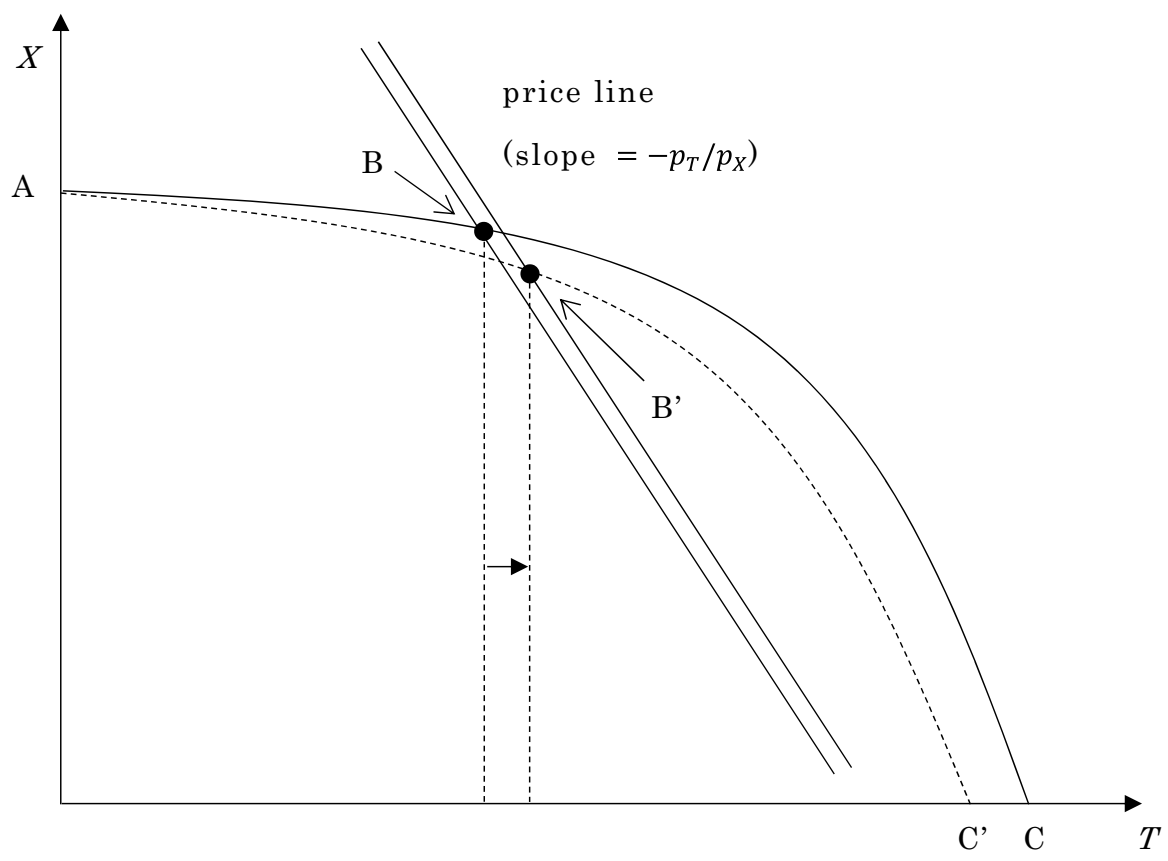

Fig. 2 The case of a stricter environmental regulation increasing the total revenue 
Table 2 The effects of an increase in $p_{T}$

\begin{tabular}{llllllll}
\hline & $\hat{X}$ & $\widehat{T}$ & $\hat{M}$ & $\widehat{w}_{S}$ & $\widehat{w}_{L}$ & $\widehat{q}$ & $\hat{r}$ \\
\hline$p_{T} \uparrow$ & - & + & + & - & + & + & + \\
\hline
\end{tabular}

Proposition 3 An improvement in the tourism terms of trade expands the tourism and tourism infrastructure sectors, while it contracts the manufacturing sector. This narrows the wage inequality between skilled and unskilled labor. The rental rate of capital and the price of emission permits rise.

The intuition is straightforward. The improvement in the tourism terms of trade expands the tourism sector and, thus, the wage of unskilled labor and the price of emission permits rise. The revenue from selling pollution permits $r Z$ and the output of tourism infrastructure increase at the expense of the manufacturing sector; this leads to a decrease in the wage of skilled labor. Since the price of the manufacturing good is unchanged, the rental rate of capital rises.

\section{Total effect of the environmental regulation}

\subsection{The effects on the tourism terms of trade and welfare}

The previous sections treated the tourism terms of trade $p_{T}$ as a constant. However, $p_{T}$ is eventually determined by the market equilibrium condition of the domestic tourism service, that is, the supply of and demand for it. In this subsection, we consider the effects of the stricter environmental regulation, considering that $p_{T}$ is not a constant.

To determine the price of the tourism service, we need to introduce the demand side of the economy. Suppose that both domestic residents and foreign tourists consume the manufacturing good and the domestic tourism service. The demand side of the economy is represented by the expenditure function of domestic residents and the demand function of foreign tourists. The expenditure function is defined as ${ }^{17}$

$$
E\left(p_{T}, Z, u\right) \equiv \min \left[p_{X} C_{X}+p_{T} C_{T} \mid u=\ln C_{X}+Z^{a} \ln C_{T}\right],
$$

where $C_{X}$ is the consumption of the manufacturing good by domestic residents, $C_{T}$ the consumption of the domestic tourism service by domestic residents, and $u$ the level of utility. $a<0$ is a parameter. The utility function has the property that the marginal utility from the tourism service decreases with the amount of pollution. For the marginal utility of pollution to be negative $\left(\frac{\partial u}{\partial Z}<0\right)$, we assume $C_{T}>1$. The expenditure function is derived as follows:

17 This specification of the utility function is suggested by Noritsugu Nakanishi. 


$$
E=\left(1+Z^{a}\right)\left(e^{u} p_{X}\right)^{\frac{1}{1+Z^{a}}}\left(\frac{p_{T}}{Z^{a}}\right)^{\frac{Z^{a}}{1+Z^{a}}} .
$$

Applying the envelope theorem, we obtain the compensated demand for the tourism service: $E_{T} \equiv \frac{\partial E}{\partial p_{T}}=C_{T}=\left(\frac{e^{u} Z^{a} p_{X}}{p_{T}}\right)^{\frac{1}{1+Z^{a}}}$. The downward sloping demand function implies $E_{T T} \equiv \partial^{2} E / \partial p_{T}^{2}<0 . E_{Z} \equiv \frac{\partial E}{\partial Z}=-\frac{a Z^{a-1} E}{\left(1+Z^{a}\right)^{2}} \ln \left(\frac{e^{u} Z^{a} p_{X}}{p_{T}}\right)>0$ denotes the marginal damage to domestic residents caused by pollution. $E_{u} \equiv \frac{\partial E}{\partial u}>0$ represents the inverse of the marginal utility of income. The effect of the stricter environmental regulation on the compensated demand for the tourism service is given by

$$
\frac{\partial C_{T}}{\partial Z}=E_{T Z} \equiv \frac{\partial^{2} E}{\partial Z \partial p_{T}}=-\frac{a Z^{a-1} C_{T}}{\left(1+Z^{a}\right)^{2}} \ln \left(\frac{e^{u} Z^{a} p_{X}}{p_{T}}\right)+\frac{a C_{T}}{\left(1+Z^{a}\right) Z} .
$$

The first term indicates the effect that a decrease in pollution reduces the amount of compensated demand required to offset the disutility from pollution, while the second term indicates that the decrease in pollution raises the attractiveness of the tourism service. If the latter effect outweighs the former, the stricter environmental regulation increases the compensated demand for the tourism service. ${ }^{18}$

Foreign tourists also consume the manufacturing good and the domestic tourism service. Their utility function is given by $u^{*}=\ln D_{X}+Z^{\alpha} \ln D_{T}$, where $D_{X}$ is the consumption of the manufacturing good by foreign tourists, and $D_{T}$ is the consumption of the domestic tourism service by foreign tourists. $\alpha<0$ is a parameter. For the marginal utility of pollution to be negative, we assume $D_{T}>1$. Foreign tourists' demand for the domestic tourism service is derived as $D_{T}=\frac{Z^{\alpha}}{1+Z^{\alpha}} \frac{Y^{*}}{p_{T}}$, where $Y^{*}$ is the budget of foreign tourists and is exogenously given. Note that $\frac{\partial D_{T}}{\partial Z}<0$ because a decrease in pollution increases the attractiveness of the tourism service. ${ }^{19}$

The supply side of the economy is characterized by the revenue function:

$$
R\left(p_{T}, Z\right) \equiv \max \left[p_{X} X+p_{T} T \mid K_{X}+K_{M}=K, X=X\left(K_{X}, S\right), T=g\left(K_{M} / a_{K M}\right) N(L, Z)\right] .
$$

The usual envelope theorem does not necessarily hold as the Lindahl pricing rule is not assumed. The properties of the revenue function with a positive externality of the tourism infrastructure are given in Appendix C.

Now, we can derive the equilibrium conditions for both the demand and supply sides of the economy. First, the budget constraint of the economy is given by

\footnotetext{
18 Beladi et al. (2009) and Chao et al. (2008) assume a multiplicative utility function $U\left(C_{X}, C_{T}, Z\right)=v\left(C_{X}, C_{T}\right) / h(Z)$ while Chao et al. (2012) and Chao and Sgro (2013) adopt an additively separable utility function $U\left(C_{X}, C_{T}, Z\right)=v\left(C_{X}, C_{T}\right)-h(Z)$, where $h^{\prime}(Z)>0$. If $v\left(C_{X}, C_{T}\right)$ is a CobbDouglas function, the compensated demand for the tourism service unambiguously increases with the amount of pollution, that is, $E_{T Z}>0$. See Yanase (2017, note 15).

${ }^{19}$ If the foreign tourists' utility function is a multiplicative form $U^{*}\left(D_{X}, D_{T}, Z\right)=v^{*}\left(D_{X}, D_{T}\right) / h^{*}(Z)$ or an additively separable form $U^{*}\left(D_{X}, D_{T}, Z\right)=v^{*}\left(D_{X}, D_{T}\right)-h^{*}(Z)$, where $v^{*}\left(D_{X}, D_{T}\right)$ is an increasing and strictly quasi-concave function and $h^{* \prime}(Z)>0$, the ordinary demand function does not depend on the amount of pollution. This is because the marginal rate of substitution in consumption does not depend on the amount of pollution.
} 


$$
E\left(p_{T}, Z, u\right)=R\left(p_{T}, Z\right)
$$

which states that the total expenditure equals the total revenue.

Second, the market equilibrium condition of the tourism service is

$$
E_{T}\left(p_{T}, Z, u\right)+D_{T}\left(p_{T}, Z\right)=T\left(p_{T}, Z\right) .
$$

Here, the LHS denotes the demand for the domestic tourism service, while the RHS is its supply.

The above two equations simultaneously determine the tourism terms of trade $p_{T}$ and domestic welfare $u$. We analyze the effects of the stricter environmental regulation on $p_{T}$ and $u$. Totally differentiating Eqs. (37) and (38), we obtain

$$
\left(\begin{array}{cc}
-D_{T}-\Gamma \frac{\partial M}{\partial P_{T}} & E_{u} \\
-S_{T} & E_{T u}
\end{array}\right)\left(\begin{array}{c}
d p_{T} \\
d u
\end{array}\right)=\left(\begin{array}{c}
r+\Gamma \frac{\partial M}{\partial Z}-E_{Z} \\
\frac{\partial T}{\partial Z}-E_{T Z}-\frac{\partial D_{T}}{\partial Z}
\end{array}\right) d Z,
$$

where $\Gamma \equiv p_{T} \frac{\partial T}{\partial M}-p_{M}$ is the difference between the marginal value product of tourism infrastructure and its shadow price, $S_{T} \equiv \partial T / \partial p_{T}-E_{T T}-\partial D_{T} / \partial p_{T}>0$ represents the slope of the excess supply function of the tourism service, and subscripts with respect to the expenditure function denote partial derivatives, for example, $E_{T u} \equiv \partial^{2} E / \partial u \partial p_{T}$. Note that $E_{T u}>0$ is the income effect on the tourism service. Note also that $\partial T / \partial p_{T}>0$ and $\partial M / \partial p_{T}>0$ from the analysis in Sect. 3.2. Let $\Delta^{*}$ be the determinant of the $2 \times 2$ matrix on the LHS of Eq. (39). The stability condition then requires $\Delta^{*}>0 .{ }^{20}$ Solving Eq. (39), we obtain

$$
\begin{gathered}
\frac{\mathrm{d} p_{T}}{\mathrm{~d} Z}=-\frac{E_{T u}\left(E_{Z}-r-\Gamma \frac{\partial M}{\partial Z}\right)+E_{u}\left(\frac{\partial T}{\partial Z}-E_{T Z}-\frac{\partial D_{T}}{\partial Z}\right)}{\Delta^{*}} \\
=-\frac{E_{T u}\left(E_{Z}-r\right)-E_{T u} \Gamma \frac{\partial M}{\partial Z}+E_{u}\left(\frac{\partial T}{\partial Z}-E_{T Z}-\frac{\partial D_{T}}{\partial Z}\right)}{\Delta^{*}}, \\
\frac{\mathrm{d} u}{\mathrm{~d} Z}=-\frac{\left(D_{T}+\Gamma \frac{\partial M}{\partial P_{T}}\right)\left(\frac{\partial T}{\partial Z}-E_{T Z}-\frac{\partial D_{T}}{\partial Z}\right)+S_{T}\left(E_{Z}-r-\Gamma \frac{\partial M}{\partial Z}\right)}{\Delta^{*}} \\
=-\frac{D_{T}\left(\frac{\partial T}{\partial Z}-E_{T Z}-\frac{\partial D_{T}}{\partial Z}\right)+\Gamma \frac{\partial M}{\partial P_{T}}\left(\frac{\partial T}{\partial Z}-E_{T Z}-\frac{\partial D_{T}}{\partial Z}\right)+S_{T}\left(E_{Z}-r\right)-S_{T} \Gamma \frac{\partial M}{\partial Z}}{\Delta^{*}} .
\end{gathered}
$$

Emission reduction affects the tourism terms of trade and domestic welfare through the two conventional channels, as stated by Beladi et al. (2009) and Yanase (2017). On the one hand, if a pollution reduction decreases the domestic excess supply of the tourism service $\left(\frac{\partial}{\partial Z}\left(T-D_{T}-E_{T}\right)=\frac{\partial T}{\partial Z}-\frac{\partial D_{T}}{\partial Z}-E_{T Z}>0\right)$, the price of the tourism service rises. These positive terms of trade effect improve domestic welfare. On the other hand, if the marginal damage of pollution to domestic residents is

\footnotetext{
${ }^{20}$ Let $\Omega \equiv E_{T}+D_{T}-T$ be the domestic excess demand for tourism service. From Eqs. (37) and (38), we have $d p_{T} / d \Omega=-E_{u} / \Delta^{*}$. Hence, the stability of tourism service market requires $\Delta^{*}>0$.
} 
greater than the marginal cost of pollution emission $\left(E_{Z}>r\right)$, the pollution reduction increases the real income of domestic residents. This positive income effect improves the tourism terms of trade. In Eq. (40), an additional effect $\left(-E_{T u} \Gamma \frac{\partial M}{\partial Z}\right)$ exists. In the explanation below, we assume the following conditions: (1) $\Gamma>0$ (the marginal value product of tourism infrastructure is greater than its price), (2) $\partial M / \partial Z<0$ (the output of tourism infrastructure is increased by the stricter environmental regulation), and (3) $\frac{\partial T}{\partial Z}-E_{T Z}-\frac{\partial D_{T}}{\partial Z}>0$ (the excess supply of the tourism service decreases with the stricter environmental regulation). The effect of the additional term can be explained as follows: a decrease in pollution raises tourism infrastructure, which in turn increases the total revenue and, thus, demand for the tourism service. ${ }^{21}$

Next, we consider the effect on welfare. In addition to the two aforementioned conventional channels, there are two other effects. First, a decrease in the excess supply of tourism service raises the tourism terms of trade, which in turn increases tourism infrastructure $\left(\partial M / \partial p_{T}>0\right)$. Thus, the total revenue and welfare of domestic residents increase. This effect is captured by the term $\Gamma \frac{\partial M}{\partial P_{T}}\left(\frac{\partial T}{\partial Z}-E_{T Z}-\frac{\partial D_{T}}{\partial Z}\right)$. Second, an increase in tourism infrastructure directly raises total revenue and welfare. This effect is represented by the term $\left(-S_{T} \Gamma \frac{\partial M}{\partial Z}\right)$. If conditions (1)-(3) are satisfied, both these effects increase domestic welfare. Note also that both the effects arise from the difference between the marginal value product of tourism infrastructure and its price (i.e., the term $\Gamma$ ). We call the effects arising from $\Gamma$ the $\Gamma$-channel. If conditions (1)-(3) are satisfied, the $\Gamma$-channel improves the tourism terms of trade and domestic welfare.

Thus, we can establish the following proposition.

Proposition 4 In addition to the two traditional channels, there is an additional channel arising from the difference between the marginal value product of tourism infrastructure and its price. The additional channel improves the tourism terms of trade and domestic welfare if the following three conditions are satisfied: (1) the marginal value product of tourism infrastructure is greater than its price, (2) the output of tourism infrastructure is increased by a stricter environmental regulation, and (3) the excess supply of a tourism service decreases with a stricter environmental regulation.

The first condition is likely to hold when the marginal value product of the tourism infrastructure is sufficiently high. The second condition is satisfied if and only if the elasticity of substitution in the tourism industry is sufficiently low to increase revenue from selling pollution permits. The third condition tends to hold when the output of the tourism service is decreased by the stricter environmental regulation, which occurs if the elasticity of substitution in that sector is not very low. Therefore, for both conditions (2) and (3) to hold simultaneously, the elasticity of substitution

\footnotetext{
${ }^{21}$ Note that the change in total revenue is given by $d R=X d p_{X}+T d p_{T}+w_{S} d S+w_{L} d L+r d Z+$ $q d K+\Gamma d M$. See Appendix C.
} 
in the tourism sector must be a moderately small value. By numerical simulations in Appendix D, we show that there exist parameter values that satisfy the conditions from (1) to (3).

\subsection{Effects on outputs and factor prices}

In this subsection, we examine the effects of the stricter environmental regulation on outputs and factor prices, considering that the tourism terms of trade are endogenous. The total effect (including the change in tourism terms of trade) of the environmental regulation on each endogenous variable is

$$
\frac{d \Theta}{d Z}=\frac{\partial \Theta}{\partial Z}+\frac{\partial \Theta}{\partial p_{T}} \frac{d p_{T}}{d Z}
$$

or

$$
\frac{Z}{\Theta} \frac{d \Theta}{d Z}=\frac{Z}{\Theta} \frac{\partial \Theta}{\partial Z}+\frac{p_{T}}{\Theta} \frac{\partial \Theta}{\partial p_{T}} \frac{Z}{p_{T}} \frac{d p_{T}}{d Z},
$$

where $\Theta=\mathrm{X}, T, M, w_{S}, w_{L}, q, r$. The first term on the RHS represents the direct effect of the environmental regulation, while the second term represents the indirect effect that arises from the change in the tourism terms of trade. Since the sign of the direct effect is ambiguous, we consider the necessary and sufficient conditions for the indirect effect to be dominant. The indirect effect is proportional to the change in the tourism terms of trade and, thus, the indirect effect dominates the direct effect if the tourism terms of trade effect $\left|\frac{Z}{p_{T}} \frac{d p_{T}}{d Z}\right|$ is sufficiently high.

Substituting Eqs. (31) and (36) into Eq. (42) for $\Theta=w_{S}$, the stricter environmental regulation decreases the wage of skilled labor if and only if

$$
\frac{Z}{p_{T}} \frac{d p_{T}}{d Z}<\frac{\theta_{L T}-\sigma_{T}}{\sigma_{T}} \equiv D .
$$

From Eqs. (26), (27), (28), and (42) the total effects on $q, X$, and $M$ are proportional to those on $w_{S}$.

Similarly, substituting Eqs. (30), (35), and (36) into Eq. (42) for $\Theta=T$, a decrease in pollution reduces the production of tourism service $T$ if and only if

$$
\frac{Z}{p_{T}} \frac{d p_{T}}{d Z}>-\frac{\theta_{Z T}(1-\xi)+m}{\xi}+D \equiv F .
$$

Substituting Eqs. (29), (32), (34), and (36) into Eq. (42) for $\Theta=w_{L}$, the necessary and sufficient condition for a decrease in pollution to reduce the wage of unskilled labor $w_{L}$ is 


$$
\frac{Z}{p_{T}} \frac{d p_{T}}{d Z}>-\frac{\theta_{Z T}\left(1+\frac{m}{\theta_{Z T}}\right)+\xi\left(\sigma_{T}-1\right)}{\left(1+\frac{m}{\theta_{Z T}}\right) \sigma_{T}} \equiv G
$$

Finally, substituting Eqs. (33), (34), and (36) into Eq. (42) for $\Theta=r$, the amount of pollution and the price of emission permits $r$ move in the same direction if and only if

$$
\frac{Z}{p_{T}} \frac{d p_{T}}{d Z}>\frac{\theta_{L T}\left(1+\frac{m}{\theta_{Z T}}\right)-\xi \sigma_{T}}{\left(1+\frac{m}{\theta_{Z T}}\right) \sigma_{T}} \equiv H .
$$

By the straightforward calculation, we have $H-D=\frac{1-\xi+m / \theta_{Z T}}{1+m / \theta_{Z T}}>0$ and $H-G=\frac{1-\xi+m / \theta_{Z T}}{\sigma_{T}\left(1+m / \theta_{Z T}\right)}>0$. From this, it is easy to show that $F<D<H$. It follows that there are three cases to be considered: (1) when $\sigma_{T}<\frac{\xi}{\theta_{Z T}+m+\xi}, G<F<D<H$; (2) when $\frac{\xi}{\theta_{Z T}+m+\xi}<\sigma_{T}<1, F<G<D<H$; and (3) when $\sigma_{T}>1, F<D<G<H$. The results are summarized in Tables 3,4 and $5 .^{22}$

The above results are summarized by the following proposition.

Proposition 5 When $\frac{Z}{p_{T}} \frac{d p_{T}}{d Z}<\min (F, G)$, a stricter environmental regulation expands the tourism and tourism infrastructure sectors while it contracts the manufacturing sector. It narrows the wage inequality between skilled and unskilled labor. The rental rate of capital and the price of emission permits rise. If $\frac{Z}{p_{T}} \frac{d p_{T}}{d Z}>H$, all the above results are reversed.

Focusing on the total effect on domestic wage inequality, we have the following proposition.

Proposition 6 When $\frac{Z}{p_{T}} \frac{d p_{T}}{d Z} \leq \min (D, G)$, a stricter environmental regulation unambiguously narrows domestic wage inequality. However, if $\frac{Z}{p_{T}} \frac{d p_{T}}{d Z} \geq \max (D, G)$, there is a trade-off between reducing pollution and narrowing wage inequality.

If the tourism terms of trade improve significantly, a stricter environmental regulation can provide a further benefit in improving domestic welfare. ${ }^{23}$ This result is consistent with those of Chao et al. (2012) and Nakai et al. (2018).

When the production function of the tourism sector is Cobb-Douglas (i.e., $\sigma_{T}=1$ ), the above analysis becomes quite simple (see Appendix E). In this case, at

\footnotetext{
22 Straight calculation shows that $G-F>0 \leftrightarrow \sigma_{T}>\frac{\xi}{\theta_{Z T}+m+\xi}(>A)$ and $D-G>0 \leftrightarrow \sigma_{T}<1$.

23 Differentiating Eq. (37) and substituting Eq. (38), we obtain $\left(E_{Z}-r-\Gamma \frac{\partial M}{\partial Z}\right) \mathrm{d} Z-\left(E_{Z}-r-\Gamma \frac{\partial M}{\partial Z}\right) \mathrm{d} Z$. It follows that, ceteris paribus, an improvement in tourism terms of trade raises domestic welfare.
} 
Table 3 The case of $\sigma_{T}<\frac{\xi}{\theta_{Z T}+m+\xi}$

Table 4 The case of $\frac{\xi}{\theta_{Z T}+m+\xi}<\sigma_{T}<1$

Table 5 The case of $\sigma_{T}>1$

\begin{tabular}{llllllllll}
\hline$\frac{Z}{p_{T}} \frac{d p_{T}}{d Z}$ & - & $G$ & - & $F$ & - & $D$ & - & $H$ & - \\
\hline$d T / d Z$ & - & - & - & 0 & + & + & + & + & + \\
$d w_{S} / d Z$ & + & + & + & + & + & 0 & - & - & - \\
$d w_{L} / d Z$ & - & 0 & + & + & + & + & + & + & + \\
$d r / d Z$ & - & - & - & - & - & - & - & 0 & + \\
\hline
\end{tabular}

\begin{tabular}{lllllllllll}
\hline$\underline{Z} \frac{d p_{T}}{d Z}$ & - & $F$ & - & $G$ & - & $D$ & - & $H$ & - \\
\hline$d T / d Z$ & - & 0 & + & + & + & + & + & + & + \\
$d w_{S} / d Z$ & + & + & + & + & + & 0 & - & - & - \\
$d w_{L} / d Z$ & - & - & - & 0 & + & + & + & + & + \\
$d r / d Z$ & - & - & - & - & - & - & - & 0 & + \\
\hline
\end{tabular}

\begin{tabular}{llllllllll}
\hline$\underline{Z} \frac{d p_{T}}{d Z}$ & - & $F$ & - & $D$ & - & $G$ & - & $H$ & - \\
\hline$d T / d Z$ & - & 0 & + & + & + & + & + & + & + \\
$d w_{S} / d Z$ & + & + & + & 0 & - & - & - & - & - \\
$d w_{L} / d Z$ & - & - & - & - & - & 0 & + & + & + \\
$d r / d Z$ & - & - & - & - & - & - & - & 0 & + \\
\hline
\end{tabular}

constant tourism terms of trade, the effect of the stricter environmental regulation on the price of pollution permits is ambiguous. However, the revenue from pollution permits $r Z$ unambiguously declines, leading to a decrease in the output of tourism infrastructure. This results in a decline in the output of the tourism service and the wage of unskilled labor. At the same time, capital flows from the tourism infrastructure sector to the traded good sector. It follows that the output of the traded good and the wage of skilled labor rise.

\section{Conclusions}

This study sets up a small open developing tourism economy with tourism infrastructure and examines the welfare, production, and income distribution effects of a stricter environmental policy. The tourism sector generates pollution in the sense that it requires pollution as an input. Since the Lindahl pricing rule is not assumed, the usual envelope theorem and reciprocity relationship do not necessarily hold. Thus, we can obtain interesting comparative static results. If the elasticity of substitution in the tourism sector is sufficiently low, a stricter environmental regulation paradoxically expands the tourism sector even under the constant tourism terms of trade. At the same time, the wage inequality between skilled and unskilled labor narrows. 
This study provides new insights regarding welfare concerns. In addition to the two conventional channels pointed out by Beladi et al. (2009) and Yanase (2017), this study contains an additional channel through which a stricter environmental regulation affects the tourism terms of trade and domestic welfare. Furthermore, the new channel, which arises from the difference between the marginal value product of tourism infrastructure and its price, increases the tourism terms of trade and domestic welfare if (1) the marginal value product of tourism infrastructure is greater than its price, (2) the output of tourism infrastructure is increased by a stricter environmental regulation, and (3) the excess supply of a tourism service decreases with a stricter environmental regulation.

Before closing this paper, we will state some topics for future research. In this study, we have considered that tourism infrastructure only enhances the productivity of the tourism industry and includes no congestion effect. However, some tourism infrastructures such as airports and highways contribute to several industries and include the congestion effect, where an increase in users lowers efficiency. Thus, it is important to consider this type of infrastructure. If the infrastructure contributes to almost all industries in the economy, the national government can finance the cost of infrastructure by taxing the income of residents in the economy.

We assume that the tourism industry is under perfect competition. It will be interesting to consider another market structure, for example, duopoly or monopolistic competition cases. $^{24,25}$

We have considered only environmental regulation as the national government's policy instrument. It may be possible to consider an optimal policy mix of environmental regulation and import tariff, as in Chao et al. (2008) and Yanase (2017).

In this study, pollution is emitted from the production of the tourism service. However, if pollution is generated from consumption, the corresponding environmental policy may be a consumption tax or license fee to enter a tourist spot. The analysis of consumption tax or license fee would yield new results. All these issues are left for future research.

\section{Appendices}

\section{Appendix A. Derivation of Eqs. (30)-(33), and (36)}

Let $\Delta$ be the determinant of the $7 \times 7$ matrix on the LHS of Eq. (25):

\footnotetext{
${ }^{24}$ Chao et al. (2012) assumed that tourism industry is under oligopoly.

25 Some tourism industries (e.g., hotel and travel agency business) consist of many agents (see Japan Fair Trade Commission (2016)). Therefore, it is reasonable to consider tourism industry to be under perfect competition or monopolistic competition.
} 


$$
\Delta \equiv\left|\begin{array}{ccccccc}
0 & 0 & 0 & \theta_{S X} & 0 & \theta_{K X} & 0 \\
0 & 0 & -\xi & 0 & \theta_{L T} & 0 & \theta_{Z T} \\
\lambda_{K X} & 0 & \lambda_{K M} & \lambda_{K X} \theta_{S X} \sigma_{X} & 0 & -\lambda_{K X} \theta_{S X} \sigma_{X} & 0 \\
1 & 0 & 0 & -\theta_{K X} \sigma_{X} & 0 & \theta_{K X} \sigma_{X} & 0 \\
0 & 1 & -\xi & 0 & -\theta_{Z T} \sigma_{T} & 0 & \theta_{Z T} \sigma_{T} \\
0 & 1 & -\xi & 0 & \theta_{L T} \sigma_{T} & 0 & -\theta_{L T} \sigma_{T} \\
0 & 0 & 1 & 0 & 0 & 1 & -1
\end{array}\right|
$$

Add the fourth column to the sixth column and then the fifth column to the seventh column to obtain

$$
=\left|\begin{array}{ccccccc}
0 & 0 & 0 & \theta_{S X} & 0 & 1 & 0 \\
0 & 0 & -\xi & 0 & \theta_{L T} & 0 & 1 \\
\lambda_{K X} & 0 & \lambda_{K M} & \lambda_{K X} \theta_{S X} \sigma_{X} & 0 & 0 & 0 \\
1 & 0 & 0 & -\theta_{K X} \sigma_{X} & 0 & 0 & 0 \\
0 & 1 & -\xi & 0 & -\theta_{Z T} \sigma_{T} & 0 & 0 \\
0 & 1 & -\xi & 0 & \theta_{L T} \sigma_{T} & 0 & 0 \\
0 & 0 & 1 & 0 & 0 & 1 & -1
\end{array}\right|
$$

Subtract the fifth row from the sixth row to obtain

$$
=\left|\begin{array}{ccccccc}
0 & 0 & 0 & \theta_{S X} & 0 & 1 & 0 \\
0 & 0 & -\xi & 0 & \theta_{L T} & 0 & 1 \\
\lambda_{K X} & 0 & \lambda_{K M} & \lambda_{K X} \theta_{S X} \sigma_{X} & 0 & 0 & 0 \\
1 & 0 & 0 & -\theta_{K X} \sigma_{X} & 0 & 0 & 0 \\
0 & 1 & -\xi & 0 & -\theta_{Z T} \sigma_{T} & 0 & 0 \\
0 & 0 & 0 & 0 & \sigma_{T} & 0 & 0 \\
0 & 0 & 1 & 0 & 0 & 1 & -1
\end{array}\right|
$$

Expand by the second column to obtain

$$
=-\left|\begin{array}{cccccc}
0 & 0 & \theta_{S X} & 0 & 1 & 0 \\
0 & -\xi & 0 & \theta_{L T} & 0 & 1 \\
\lambda_{K X} & \lambda_{K M} & \lambda_{K X} \theta_{S X} \sigma_{X} & 0 & 0 & 0 \\
1 & 0 & -\theta_{K X} \sigma_{X} & 0 & 0 & 0 \\
0 & 0 & 0 & \sigma_{T} & 0 & 0 \\
0 & 1 & 0 & 0 & 1 & -1
\end{array}\right| .
$$

Expand by the fifth row to obtain

$$
=\sigma_{T}\left|\begin{array}{ccccc}
0 & 0 & \theta_{S X} & 1 & 0 \\
0 & -\xi & 0 & 0 & 1 \\
\lambda_{K X} & \lambda_{K M} & \lambda_{K X} \theta_{S X} \sigma_{X} & 0 & 0 \\
1 & 0 & -\theta_{K X} \sigma_{X} & 0 & 0 \\
0 & 1 & 0 & 1 & -1
\end{array}\right| .
$$

Add the second row to the fifth row to obtain 


$$
=\sigma_{T}\left|\begin{array}{ccccc}
0 & 0 & \theta_{S X} & 1 & 0 \\
0 & -\xi & 0 & 0 & 1 \\
\lambda_{K X} & \lambda_{K M} & \lambda_{K X} \theta_{S X} \sigma_{X} & 0 & 0 \\
1 & 0 & -\theta_{K X} \sigma_{X} & 0 & 0 \\
0 & 1-\xi & 0 & 1 & 0
\end{array}\right|
$$

Expand by the fifth column to obtain

$$
=-\sigma_{T}\left|\begin{array}{cccc}
0 & 0 & \theta_{S X} & 1 \\
\lambda_{K X} & \lambda_{K M} & \lambda_{K X} \theta_{S X} \sigma_{X} & 0 \\
1 & 0 & -\theta_{K X} \sigma_{X} & 0 \\
0 & 1-\xi & 0 & 1
\end{array}\right| .
$$

Multiply the third row by $\lambda_{K X}$ and then subtract from the second row to obtain

$$
=-\sigma_{T}\left|\begin{array}{cccc}
0 & 0 & \theta_{S X} & 1 \\
0 & \lambda_{K M} & \lambda_{K X} \sigma_{X} & 0 \\
1 & 0 & -\theta_{K X} \sigma_{X} & 0 \\
0 & 1-\xi & 0 & 1
\end{array}\right| .
$$

Expand by the first column to obtain

$$
=-\sigma_{T}\left|\begin{array}{ccc}
0 & \theta_{S X} & 1 \\
\lambda_{K M} & \lambda_{K X} \sigma_{X} & 0 \\
1-\xi & 0 & 1
\end{array}\right|=\sigma_{T}\left[(1-\xi) \lambda_{K X} \sigma_{X}+\lambda_{K M} \theta_{S X}\right]>0 .
$$

By the Cramer's rule, the numerator of $\widehat{T} / \widehat{Z}$ is

$$
\begin{aligned}
& \left|\begin{array}{ccccccc}
0 & 0 & 0 & \theta_{S X} & 0 & \theta_{K X} & 0 \\
0 & 0 & -\xi & 0 & \theta_{L T} & 0 & \theta_{Z T} \\
\lambda_{K X} & 0 & \lambda_{K T} & \lambda_{K X} \theta_{S X} \sigma_{X} & 0 & -\lambda_{K X} \theta_{S X} \sigma_{X} & 0 \\
1 & 0 & 0 & -\theta_{K X} \sigma_{X} & 0 & \theta_{K X} \sigma_{X} & 0 \\
0 & 0 & -\xi & 0 & -\theta_{Z T} \sigma_{T} & 0 & \theta_{Z T} \sigma_{T} \\
0 & 1 & -\xi & 0 & \theta_{L T} \sigma_{T} & 0 & -\theta_{L T} \sigma_{T} \\
0 & 1 & 1 & 0 & 0 & 1 & -1
\end{array}\right| \\
& =(1-\xi) \theta_{Z T} \sigma_{T} \lambda_{K X} \sigma_{X}+\theta_{S X} \theta_{Z T} \sigma_{T} \lambda_{K M}+\xi\left(\sigma_{T}-\theta_{L T}\right) \lambda_{K X} \sigma_{X} .
\end{aligned}
$$

Similarly, the numerator of $\widehat{w}_{S} / \widehat{Z}$ is

$$
\left|\begin{array}{ccccccc}
0 & 0 & 0 & 0 & 0 & \theta_{K X} & 0 \\
0 & 0 & -\xi & 0 & \theta_{L T} & 0 & \theta_{Z T} \\
\lambda_{K X} & 0 & \lambda_{K M} & 0 & 0 & -\lambda_{K X} \theta_{S X} \sigma_{X} & 0 \\
1 & 0 & 0 & 0 & 0 & \theta_{K X} \sigma_{X} & 0 \\
0 & 1 & -\xi & 0 & -\theta_{Z T} \sigma_{T} & 0 & \theta_{Z T} \sigma_{T} \\
0 & 1 & -\xi & 1 & \theta_{L T} \sigma_{T} & 0 & -\theta_{L T} \sigma_{T} \\
0 & 0 & 1 & 1 & 0 & 1 & -1
\end{array}\right|=\theta_{K X} \lambda_{K M}\left(\theta_{L T}-\sigma_{T}\right) .
$$

The numerator of $\widehat{w}_{L} / \widehat{Z}$ is 


$$
\left|\begin{array}{ccccccc}
0 & 0 & 0 & \theta_{S X} & 0 & \theta_{K X} & 0 \\
0 & 0 & -\xi & 0 & 0 & 0 & \theta_{Z T} \\
\lambda_{K X} & 0 & \lambda_{K M} & \lambda_{K X} \theta_{S X} \sigma_{X} & 0 & -\lambda_{K X} \theta_{S X} \sigma_{X} & 0 \\
1 & 0 & 0 & -\theta_{K X} \sigma_{X} & 0 & \theta_{K X} \sigma_{X} & 0 \\
0 & 1 & -\xi & 0 & 0 & 0 & \theta_{Z T} \sigma_{T} \\
0 & 1 & -\xi & 0 & 1 & 0 & -\theta_{L T} \sigma_{T} \\
0 & 0 & 1 & 0 & 1 & 1 & -1
\end{array}\right|=\lambda_{K X} \sigma_{X}\left[\theta_{Z T}+\xi\left(\sigma_{T}-1\right)\right]+\lambda_{K M} \theta_{S X} \theta_{Z T}
$$

The numerator of $\widehat{r} / \widehat{Z}$ is

$$
\left|\begin{array}{ccccccc}
0 & 0 & 0 & \theta_{S X} & 0 & \theta_{K X} & 0 \\
0 & 0 & -\xi & 0 & \theta_{L T} & 0 & 0 \\
\lambda_{K X} & 0 & \lambda_{K M} & \lambda_{K X} \theta_{S X} \sigma_{X} & 0 & -\lambda_{K X} \theta_{S X} \sigma_{X} & 0 \\
1 & 0 & 0 & -\theta_{K X} \sigma_{X} & 0 & \theta_{K X} \sigma_{X} & 0 \\
0 & 1 & -\xi & 0 & -\theta_{Z T} \sigma_{T} & 0 & 0 \\
0 & 1 & -\xi & 0 & \theta_{L T} \sigma_{T} & 0 & 1 \\
0 & 0 & 1 & 0 & 0 & 1 & 1
\end{array}\right|=\xi \sigma_{T} \lambda_{K X} \sigma_{X}-\theta_{L T} \lambda_{K M} \theta_{S X}-\lambda_{K X} \sigma_{X} \theta_{L T}
$$

The numerator of $\widehat{w}_{S} / \widehat{p}_{T}$ is

$$
\left|\begin{array}{ccccccc}
0 & 0 & 0 & 0 & 0 & \theta_{K X} & 0 \\
0 & 0 & -\xi & 1 & \theta_{L T} & 0 & \theta_{Z T} \\
\lambda_{K X} & 0 & \lambda_{K M} & 0 & 0 & -\lambda_{K X} \theta_{S X} \sigma_{X} & 0 \\
1 & 0 & 0 & 0 & 0 & \theta_{K X} \sigma_{X} & 0 \\
0 & 1 & -\xi & 0 & -\theta_{Z T} \sigma_{T} & 0 & \theta_{Z T} \sigma_{T} \\
0 & 1 & -\xi & 0 & \theta_{L T} \sigma_{T} & 0 & -\theta_{L T} \sigma_{T} \\
0 & 0 & 1 & 0 & 0 & 1 & -1
\end{array}\right|=-\theta_{K X} \lambda_{K M} \sigma_{T}<0
$$

\section{Appendix B. Shape of the production possibility curve}

The first-order conditions for profit maximization in manufacturing sector are

$$
\begin{aligned}
& p_{X} \frac{\partial X}{\partial S}=w_{S}, \\
& p_{X} \frac{\partial X}{\partial K_{X}}=q .
\end{aligned}
$$

Similarly, the first-order conditions for profit maximization in the tourism sector are

$$
\begin{gathered}
p_{T} \frac{\partial T}{\partial L}=w_{L}, \\
p_{T} \frac{\partial T}{\partial Z}=r .
\end{gathered}
$$


Therefore, we have $\mathrm{e}^{26}$

$$
p_{X} d X+p_{T} d T=w_{S} d S+w_{L} d L+r d Z+q d K+\Gamma d M,
$$

where $\Gamma \equiv p_{T} \frac{\partial T}{\partial M}-p_{M}$ is the difference between the marginal value product of tourism infrastructure and its price. Using the budget constraint of the government (8), we can rewrite $\Gamma=p_{M}\left(\frac{\xi}{\theta_{Z T}}-1\right)$. Keeping the factor endowments unchanged, the slope of the production possibility curve is given by

$$
\frac{d X}{d T}=-\frac{p_{T}}{p_{X}}+\frac{\Gamma}{p_{X}} \frac{d M}{d T}=-\frac{p_{T}}{p_{X}} \frac{\theta_{Z T}}{\xi},
$$

where we have used Eq. (8) and $\frac{d M}{d T}=\frac{\widehat{M}}{\widehat{T}} \frac{M}{T}=\frac{M}{T \xi}$ from Eqs. (22) and (29). Equation (B.6) implies that the production possibility curve is flatter than the price line if and only if $\Gamma>0$ (i.e., $\xi>\theta_{Z T}$ ).

The absolute value of the slope of the production possibility curve is rewritten as

$$
\frac{p_{T}}{p_{X}} \frac{\theta_{Z T}}{\xi}=\frac{r a_{Z T}}{p_{X} \xi}
$$

where the rate of change of the RHS is given by ${ }^{27}$

$$
\hat{r}+\hat{a}_{Z T}-\hat{p}_{X}-\hat{\xi}=\left[\frac{\theta_{S X} \lambda_{K M}}{\lambda_{K X} \sigma_{X}}-\frac{g^{\prime \prime} M}{g^{\prime}}\right] \hat{M}=\left[\frac{\theta_{S X} \lambda_{K M}}{\lambda_{K X} \sigma_{X}}-\frac{g^{\prime \prime} M}{g^{\prime}}\right] \frac{\hat{T}}{\xi} .
$$

Therefore, we can conclude that $\mathrm{d}^{2} X / \mathrm{d} T^{2}<0$. It follows that the production possibility curve is strictly concave to the origin.

\section{Appendix C. Properties of the revenue function}

The total revenue is defined as

$$
R=p_{X} X+p_{T} T
$$

Considering Eq. (B.5), the change in the total revenue is given by

$$
d R=X d p_{X}+T d p_{T}+w_{S} d S+w_{L} d L+r d Z+q d K+\Gamma d M .
$$

The last term in Eq. (C.1) implies that an increase in tourism infrastructure raises the total revenue $R$ if and only if the marginal value product of tourism infrastructure is larger than its price (i.e., $p_{T} \frac{\partial T}{\partial M}>p_{M}$ ).

From Eq. (C.1), we obtain

\footnotetext{
${ }^{26}$ We have used Eqs. (3) and (4).

${ }^{27}$ We have used Eqs. (16), (17), (20), (21) and (24). Also note that $\widehat{w}_{L}=\widehat{r}$ from Eq. (29). Substituting $\widehat{w}_{L}=\widehat{r}$ into Eq. (22) yields $\widehat{M}=\widehat{T} / \xi$.
} 


$$
\begin{gathered}
\frac{\partial R}{\partial p_{T}} \equiv R_{T}=T+\Gamma \frac{\partial M}{\partial p_{T}}, \\
\frac{\partial R}{\partial Z} \equiv R_{Z}=r+\Gamma \frac{\partial M}{\partial Z} .
\end{gathered}
$$

Thus, the envelope theorem holds if $\Gamma=0$.

\section{Appendix D. Numerical simulations}

Since conditions (2) and (3) in Proposition 4.1 seem to be inconsistent with each other, we resort to numerical simulations to find out a set of parameter values that satisfy the conditions from (1) to (3). Numerical Simulations utilize MATLAB R2021a.

For this purpose, we specify the production function. Suppose that the production function of the traded good is a Cobb-Douglas function

$$
X=A_{X} S^{\delta}\left(K_{X}\right)^{1-\delta},
$$

where $A_{X}$ denotes the productivity parameter for the traded good sector, and $\delta \in(0,1)$ is the factor cost share of skilled labor. Thus, we have $\theta_{S X}=\delta$ and $\theta_{K X}=1-\delta$. The associated unit cost is then given by $\frac{\left(w_{S}\right)^{\delta} q^{1-\delta}}{A_{X} \delta^{\delta}(1-\delta)^{1-\delta}}$.

The production function of the tourism service is assumed to be the constant elasticity of substitution (CES) function:

$$
T=M^{\xi}\left[\gamma L^{-\rho}+(1-\gamma) Z^{-\rho}\right]^{-1 / \rho},
$$

where $\gamma \in(0,1)$ and $\rho \geq-1$ are parameters. It is well known that the elasticity of substitution is $\sigma_{T}=1 /(1+\rho)$. We specify $g(M)=M^{\xi}$, where $\xi \in(0,1)$ is a constant.

From Eqs. (6) and (7), we obtain

$$
\frac{a_{L T}}{a_{Z T}}=\frac{L}{Z} .
$$

Substituting Eqs. (7) and (D.3) into Eq. (D.2), we obtain

$$
a_{Z T}=M^{-\xi}\left[\gamma(Z / L)^{\rho}+1-\gamma\right]^{1 / \rho} .
$$

The cost minimization in the tourism sector yields

$$
\frac{w_{L}}{r}=\frac{\gamma}{1-\gamma}\left(\frac{a_{Z T}}{a_{L T}}\right)^{1+\rho} .
$$

Substituting Eqs. (D.3)-(D.5) into Eq. (2) yields 


$$
p_{T}=\frac{r}{1-\gamma} M^{-\xi}\left[\gamma(Z / L)^{\rho}+1-\gamma\right]^{\frac{1+\rho}{\rho}}
$$

Substituting Eq. (D.4) into Eq. (7), we obtain

$$
M^{-\xi}\left[\gamma(Z / L)^{\rho}+1-\gamma\right]^{1 / \rho} T=Z .
$$

Substituting Eq. (3) into Eq. (8), we have

$$
r Z=q a_{K M} M
$$

The zero-profit condition for the traded good industry (1) is rewritten as

$$
\frac{\left(w_{S}\right)^{\delta} q^{1-\delta}}{A_{X} \delta^{\delta}(1-\delta)^{1-\delta}}=p_{X} .
$$

Substituting Eq. (D.9) and taking into account that the factor cost share of capital in the traded good sector is $1-\delta$, the full employment condition of capital (4) can be rewritten as

$$
(1-\delta) p_{X} X+r Z=q K .
$$

Considering that the factor cost share of skilled labor in the traded good sector is $\delta$, the demand-supply equality of skilled labor (5) becomes

$$
\delta p_{X} X=w_{S} S .
$$

The utility function of domestic residents is specified as

$$
u=\ln C_{X}+\frac{1}{Z} \ln C_{T} .
$$

For the marginal utility of pollution to be negative, we assumed $C_{T}>1$. The utility maximization yields

$$
Z p_{T} C_{T}=p_{X} C_{X}
$$

Suppose that the utility function of foreign tourists is given by

$$
u^{*}=\ln D_{X}+\frac{1}{Z} \ln D_{T} .
$$

Similarly, we assumed $D_{T}>1$. The tourists' ordinary demand function for the tourism service is derived as

$$
D_{T}=\frac{1}{1+Z} \frac{Y^{*}}{p_{T}}
$$

The market-clearing condition for the tourism service is given by

$$
C_{T}+D_{T}=T \text {. }
$$


The budget constraint of the economy is

$$
p_{X} X+p_{T} T=p_{X} C_{X}+p_{T} C_{T} .
$$

Equations (D.6)-(D.15) determine $X, T, w_{S}, q, r, M, p_{T}, C_{X}, C_{T}$, and $D_{T}$. We set the parameter values as follows: $A_{X}=1, p_{X}=1, \delta=\gamma=0.6, \xi=0.8, \rho=3, L=3$, $S=1, K=25, a_{K M}=2, Y^{*}=4$, and $Z=2.5$. The elasticity of substitution in the tourism sector is $\sigma_{T}=1 /(1+\rho)=0.25$. The factor cost share of emission permits in the tourism sector is calculated as $\theta_{Z T}=\frac{1}{\frac{\gamma}{1-\gamma}\left(\frac{Z}{L}\right)^{\rho}+1}=0.5353$. Since $\xi>\theta_{Z T}$, condition (1) is satisfied. By the definition, $\theta_{L T}=1-\theta_{Z T}=0.4647$. Then, $\sigma_{T}<\theta_{L T}$, implying that condition (2) holds. Finally, $\frac{\partial}{\partial Z}\left(T-C_{T}-D_{T}\right)=1.343>0$. Therefore, condition (3) holds.

\section{Appendix $E$. The case where the production function of tourism sector is Cobb-Douglas}

When the production function of the tourism industry is Cobb-Douglas, that is, $\sigma_{T}=1$, the comparative static results in Sect. 3.1, where the tourism terms of trade are fixed, are simplified as

$$
\begin{gathered}
\frac{\widehat{T}}{\widehat{Z}}=\frac{\theta_{Z T}\left(\lambda_{K X} \sigma_{X}+\theta_{S X} \lambda_{K M}\right)}{\Delta}>0, \\
\frac{\widehat{w}_{S}}{\widehat{Z}}=-\frac{\theta_{K X} \lambda_{K M} \theta_{Z T}}{\Delta}<0, \\
\frac{\hat{r}}{\widehat{Z}}=\frac{\lambda_{K X} \sigma_{X}\left(\xi-\theta_{L T}\right)-\theta_{L T} \lambda_{K M} \theta_{S X}}{\Delta} .
\end{gathered}
$$

From Eqs. (18) and (22), we obtain $\frac{\widehat{T}}{\hat{Z}}=\frac{\widehat{w}_{L}}{\widehat{Z}}$. Note also that from Eqs. (34), (36), and (E.1), the reciprocity relationship $\left(\partial T / \partial Z=\partial r / \partial p_{T}\right)$ holds in this case.

\section{The total effect}

Now, we consider the total effect of a stricter environmental regulation, taking into account the indirect effect induced by the change in the tourism terms of trade. Letting $\sigma_{T}$ be unity in Eq. (43), the necessary and sufficient condition for a reduction in pollution to decrease the wage of skilled labor is

$$
\frac{Z}{p_{T}} \frac{\mathrm{d} p_{T}}{\mathrm{~d} Z}<-\theta_{Z T} .
$$


Table 6 Total effect: the CobbDouglas production function is employed for the tourism sector

\begin{tabular}{llllllll}
\hline$Z \frac{Z}{p_{T}} \frac{d p_{T}}{d Z}$ & - & $F^{\prime}$ & - & $-\theta_{Z T}$ & - & $H^{\prime}$ & - \\
$d w_{S} / d Z$ & + & + & + & 0 & - & - & - \\
$d T / d Z$ & - & 0 & + & + & + & + & + \\
$d w_{L} / d Z$ & - & - & - & 0 & + & + & + \\
$d r / d Z$ & - & - & - & - & - & 0 & + \\
\hline
\end{tabular}

Recall that from Eqs. (26)-(28), the total effects on $q, X$, and $M$ are proportional to those on $w_{S}$.

Similarly, from Eq. (44), the stricter environmental regulation contracts the tourism industry if and only if

$$
\frac{Z}{p_{T}} \frac{\mathrm{d} p_{T}}{\mathrm{~d} Z}>-\frac{\theta_{Z T}+m}{\xi} \equiv F^{\prime} .
$$

From Eq. (45), the necessary and sufficient condition for decreasing pollution to increase the wage of unskilled labor down is

$$
\frac{Z}{p_{T}} \frac{\mathrm{d} p_{T}}{\mathrm{~d} Z}>-\theta_{Z T} .
$$

From Eq. (46), the amount of pollution and the price of emission permits move in the same direction if and only if

$$
\frac{Z}{p_{T}} \frac{\mathrm{d} p_{T}}{\mathrm{~d} Z}>\frac{\theta_{L T}\left(1+\frac{m}{\theta_{Z T}}\right)-\xi}{1+\frac{m}{\theta_{Z T}}}=\theta_{L T}-\frac{\xi}{1+\frac{m}{\theta_{Z T}}} \equiv H^{\prime} .
$$

It is straightforward to show that $F^{\prime}<-\theta_{Z T}<H^{\prime}$.

Therefore, when the production function of the tourism sector is Cobb-Douglas, Tables 3, 4 and 5 are simplified as shown in Table 6.

Acknowledgements This is a substantially revised and updated version of the paper previously entitled "Tourism infrastructure, the environment, and international trade". We are grateful to Muneyuki Saito; Shigemi Yabuuchi; and participants at the Kansai branch meeting of the Japan Society of International Economics (JSIE), Kobe International Economic Studies (KIES), and the 78th annual meeting of the JSIE for their helpful comments and suggestions. We also would like to thank Editage (www.editage. com) for English language editing. All remaining errors are ours.

Author contributions Not applicable.

Funding Not applicable.

Code availability Numerical Simulations utilize MATLAB R2021a.

Availability of data and material The data that support the findings of this study are available on the website of the Japan Fair Trade Commission. See Japan Fair Trade Commission (2016). 


\section{Declarations}

Conflict of interest No potential conflict of interest was reported by the authors.

\section{References}

Aynalem, S., Birhanu, K., \& Tesefay, S. (2016). Employment opportunities and challenges in tourism and hospitality sectors. Journal of Tourism \& Hospitality, 5(6), 1-5.

Beghin, J., \& Roland-Holst, D. (1997). Trade and pollution linkages: Piecemeal reform and optimal intervention. Canadian Journal of Economics, 30(2), 442-455.

Beladi, H., Chao, C.-C., Hazari, B. R., \& Laffargue, J.-P. (2009). Tourism and the environment. Resource and Energy Economics, 31(1), 39-49.

Beladi, H., Chau, N. H., \& Khan, M. A. (2000). North-South investment flows and optimal environmental policies. Journal of Environmental Economics and Management, 40(3), 275-296.

Beladi, H., Liu, L., \& Oladi, R. (2013). On pollution permits and abatement. Economics Letters, 119(3), 302-305.

Chao, C.-C., Hazari, B. R., Laffargue, J.-P., \& Yu, E. S. H. (2008). Environmental regulations for a small open economy with tourism. In B. Tran-Nam, N. V. Long, \& M. Tawada (Eds.), Globalization and Emerging Issues in Trade Theory and Policy (pp. 269-284). Emerald Group Publishing.

Chao, C.-C., Laffargue, J.-P., \& Sgro, P. M. (2010). Foreign aid, wage inequality, and welfare for a small open economy with tourism. Review of International Economics, 18(3), 454-464.

Chao, C.-C., Laffargue, J.-P., \& Sgro, P. M. (2012). Environmental control, wage inequality and national welfare in a tourism economy. International Review of Economics and Finance, 22(1), 201-207.

Chao, C.-C., \& Sgro, P. M. (2013). International tourism: Its costs and benefits to host countries. In C. A. Tisdell (Ed.), Handbook of Tourism Economics: Analysis, New Applications and Case Studies (pp. 605-618). World Scientific Publishing.

Copeland, B. R. (1991). Tourism, welfare and de-industrialization in a small open economy. Economica, 58(232), 515-529.

Copeland, B. R. (2011). Trade and the environment. In D. Bernhofen, R. Falvey, D. Greenaway, \& U. Kreickemeier (Eds.), Palgrave Handbook of International Trade (pp. 423-496). Palgrave Macmillan.

Copeland, B. R., \& Taylor, M. S. (2003). Trade and the Environment: Theory and Evidence. Princeton University Press.

Gupta, M. R., \& Dutta, P. B. (2018). Tourism development, environmental pollution and economic growth: A theoretical analysis. Journal of International Trade \& Economic Development, 27(2), 125-144.

International Labour Organization (ILO). (2018). Global wage report 2018/19: What lies behind gender pay gaps. Retrieved December 9, 2020, from https://www.ilo.org/wcmsp5/groups/public/---dgrep orts/---dcomm/---publ/documents/publication/wcms_650553.pdf.

Ishikawa, J., \& Kiyono, K. (2006). Greenhouse-gas emission controls in an open economy. International Economic Review, 47(2), 431-450.

Japan Fair Trade Commission. (2016). Retrieved December 9, 2020, from https://www.jftc.go.jp/soshiki/ kyotsukoukai/ruiseki/index.html.

Marjit, S., \& Acharyya, R. (2003). International trade, wage inequality and the developing economy: A general equilibrium approach. Springer-Verlag.

Meade, J. E. (1952). External economies and diseconomies in a competitive situation. Economic Journal, 62(245), 54-67.

Nakai, S., Okamoto, H., \& Shimizu, T. (2018). A comprehensive analysis of environmental policy on a small open tourism economy: Its economic welfare, terms of trade and factor rewards. Kokusai Keizai, 69, 107-132. In Japanese.

Okamoto, H. (1985). Production possibilities and international trade with public intermediate good: A generalization. The Economic Studies Quarterly, 36(1), 35-45.

Oladi, R., \& Beladi, H. (2015). On foreign aid, pollution and abatement. Environment and Development Economics, 20(6), 797-812. 
World Tourism Organization (UNWTO) and International Labour Organization (ILO). (2014). Measuring employment in the tourism industries: Guide with best practices. Retrieved December 9, 2020, from https://www.ilo.org/wcmsp5/groups/public/---ed_dialogue/---sector/documents/publication/ wcms_329309.pdf.

Yabuuchi, S. (2013). Tourism, the environment, and welfare in a dual economy. Asia-Pacific Journal of Accounting \& Economics, 20(2), 172-182.

Yabuuchi, S. (2015). Environmental protection and tourism with urban unemployment. The International Economy, 18, 31-41.

Yabuuchi, S. (2018). The effects of tourism promotion on unemployment and welfare in the presence of environmental protection and an agricultural subsidy. In B. Tran-Nam, M. Tawada, \& M. Okawa (Eds.), Recent Developments in Normative Trade Theory and Welfare Economics: New Frontiers in Regional Science (pp. 127-139). Springer.

Yanase, A. (2015). Investment in infrastructure and effects of tourism boom. Review of International Economics, 23(2), 425-443.

Yanase, A. (2017). Policy reform and optimal policy mix in a polluted small open economy with tourism. Review of International Economics, 25(3), 607-625. 